\title{
Comparative Advantage and Skill-Specific Unemployment
}

\author{
MARIO LARCH \\ WOLFGANG LECHTHALER
}

CESIFO WORKING PAPER NO. 2754

Category 8: Trade Policy

August 2009
An electronic version of the paper may be downloaded
- from the SSRN website: Www.SSRN.com
- from the RePEc website: Www.RePEc.org
- from the CESifo website: www.CESifo-group.org/wp




\title{
Comparative Advantage and Skill-Specific Unemployment
}

\begin{abstract}
We introduce unemployment and endogenous selection of workers into different skill-classes in a trade model with two sectors and heterogeneous firms. This allows us to study the distributional consequences and the skill-specific unemployment effects of trade liberalization. We show that the gains from trade will be distributed very unequally. While unskilled workers loose in terms of real wages and employment levels in the skilled labor intensive sector, skilled workers loose in terms of real wages and unemployment levels in the unskilled labor intensive sector. However, the inequality of workers between sectors is much larger for skilled labor than for unskilled labor. On average, unemployment among unskilled workers increases when a skill-abundant country opens up to trade.
\end{abstract}

JEL Code: F11, F12, F16, J64, L11.

Keywords: comparative advantage, heterogeneous firms, labor market frictions, unemployment, trade liberalization.

Mario Larch
Ifo Institute for Economic Research and
CESifo at the University of Munich
Poschingerstrasse 5
81679 Munich
Germany
larch@ifo.de

Mario Larch

o Institute for Economic Research and

Poschingerstrasse 5

Bromich

arch@ifo.de 


\section{Introduction}

The debate preceding the vote on the North American Free Trade Agreement (NAFTA) in the U.S. House of Representatives and the U.S. Senate reveals that, of the 141 anti-NAFTA statements made, 112 were of the form "NAFTA will destroy jobs" while, of the 219 pro-NAFTA statements made, 199 were of the form "NAFTA will create jobs." (Baldwin and Magee, 2000)

What are the effects of trade liberalization? The existence of gains from trade is one of the core propositions of trade theory. But at the same time the neoclassical models reveal that there are both winners and losers. While the Heckscher-Ohlin model emphasizes the role of country factor abundance and industry factor intensity for factors that are perfectly mobile between sectors, the Ricardo-Viner model assumes factors that are specific to sectors.

The distributional consequences of trade liberalization in the Heckscher-Ohlin model are summarized by the Stolper-Samuelson Theorem (Stolper and Samuelson (1941)). The Stolper-Samuelson Theorem predicts that trade liberalization will benefit an economy's relatively abundant factor and harm the economy's relatively scarce factor. This statement is true, regardless of where these factors are employed. The reason is that the factors are fully mobile between sectors. Restricting the mobility of factors leads to quite different conclusions. Assuming that some factors are specific to sectors, as the Ricardo-Viner Model does, will lead to gains for the factors that are tied to the economy's export sector and harm those factors that are tied to the economy's import sector. The reason is the immobility of factors combined with the fact that only the export sector expands after trade liberalization. However, there are several limitations when using these models for actual evaluation of trade policy consequences.

As the quotation at the beginning emphasizes, unemployment is a core issue in the political and public debate about trade liberalization. Or, as Krugman (1993) put it: "One thing that both friends and foes of free trade seem to agree on is that the central issue is employment." However, the use of frictionless factor markets in the neoclassical trade models rules out equilibrium unemployment by assumption. Further, there is no scope for firm dynamics, which makes it impossible to account for the empirical evidence that much of the observed reallocation occurs across firms within industries rather than between industries (see Attanasio, Pinelopi and Pavcnik (2004) and Levinsohn (1999)).

In this paper we present an alternative model for evaluating trade liberalization. Our model is able to make progress in the discussed limitations of the traditional models, while it is highlighting the role of the mobility assumption for the distributional consequences of trade liberalization. The model incorporates various features in order to capture the most important stylized facts. 
First, we allow for heterogeneous firms with varying productivities, generating differences in firm sizes and export status. As a consequence, trade liberalization leads to reallocation of resources not only across industries but also across firms within industries. The assumption of heterogeneous firm sizes and "selection into export markets" ${ }^{1}$ are well in line with recent empirical evidence about firms and trade (see Dunne, Roberts and Samuelson (1989); Davis and Haltiwanger (1992); Bernard and Jensen (1995, 1999, 2004); Roberts and Tybout (1997); Clerides, Lach and Tybout (1998); and Bartelsman and Doms (2000)).

Second, we assume search-and-matching frictions in the labor market, leading to equilibrium unemployment. In order to gather the gains from trade, reallocation of resources is necessary to specialize in the comparative advantage sectors. In this process of reallocation, some workers may lose their jobs. They have then to undergo a period of active job search, before they hopefully find new employment. The search and matching framework form Mortensen and Pissarides (1999), summarized in Pissarides (2000), is a useful framework to capture the idea that reallocations are associated with fricitions, leading to steady-state equilibrium unemployment.

Third, we allow for comparative advantages, by considering different sectors and factors. This gives rise to specialization patterns that highlight HeckscherOhlin forces operating not only across industries, but also across firms within industries (for recent empirical evidence see Bernard, Jensen and Schott (2006)). Allowing for different sectors and factors re-invents the reallocation of resources across industries as well as changes in relative factor rewards, which is largely ignored by the recent research on heterogeneous firms (with a notable exception given by Bernard, Redding and Schott (2007, henceforth BRS)). Hence, in the tradition of the Heckscher-Ohlin model, there is mobility of factors between sectors.

Fourth, the model incorporates an endogenous selection of people to sectors and skill-classes. We observe a wide spread of different skill compositions between countries. According to OECD (2007), the share of the population attaining the tertiary level of education can range from $20 \%$ for Slovenia to $54 \%$ for Canada. It is common in international trade to assume an exogenously given endowment of unskilled and skilled workers. However, if one focusses on the reallocation of resources due to trade liberalization in the long-run, one may want to allow for the possibility of training. Training leads unskilled workers to upgrade their skills and may improve their job opportunities by finding a high-skilled job.

Our model combines features of the models of BRS, Felbermayr and Prat (2007), Felbermayr, Prat and Schmerer (2008), Helpman and Itskhoki (2008), and Helpman, Itskhoki, and Redding (2008a,b). While BRS embed heterogeneous firms in a model of comparative advantage, and hence incorporate firm

\footnotetext{
1 "Selection into export markets" describes the fact that only the most productive firms export to foreign markets, whereas less productive firms sell there products domestically.
} 
dynamics, they stick to the assumption of perfect labor markets. Felbermayr and Prat (2007) and Felbermayr, Prat and Schmerer (2008) allow for heterogeneous firms in a one-sector economy and assume matching frictions in the labor market. Whereas the former paper assumes a closed economy, the latter assumes two symmetric countries. In the present paper, we combine the comparative advantages from BRS, i.e., allow for two potentially asymmetric countries with two sectors and two factors, with the labor market friction in a model with heterogeneous firms as in Felbermayr and Prat (2007) and Felbermayr, Prat and Schmerer (2008). ${ }^{2}$ This framework can therefore explain a) why some countries export more in certain industries than in others, why additionally intra-industry trade is observed and why some firms export and others do not and b) allows for a discussion of the unemployment and skill-composition effects of trade liberalization. Whereas the model of BRS allows to explain the facts mentioned under a) but not the ones under b), the models allowing for unemployment are able to explain the trade effects on unemployment, but not the changes in specialization and skill-composition following trade liberalization.

There are quite a few studies dealing with the unemployment effects of trade liberalization. A good overview can be found in Davidson and Matusz (2004). We just want to mention some recent developments in this debate. Egger and Kreickemeier (2008a) focus on the selection of workers into high productivity firms. In this framework they are able to explain within group inequality. Unemployment is due to a fair-wage constraint: Workers are not willing to work for a wage they judge as "unfair." They conclude, that trade liberalization not only raises unemployment, but also within group wage inequality. Egger and Kreickemeier (2008b) allow for three choices of an individual: (i) run a firm, (ii) become self-employed, (iii) be a worker. In equilibrium, the marginal individual must be indifferent between these three choices. They then study the effect on income inequality and unemployment between these groups of workers and show that international trade increases unemployment, income inequality between entrepreneurs and workers, and inequality within these two subgroups of individuals. However, in both of these papers, there is no scope for a comparative advantage of countries, as they assume only one sector and one factor of production.

Helpman, Itskhoki and Redding (2008a) have many sectors and countries, and workers that differ by an exogenously given ability, which is randomly distributed. Workers are perfectly mobile between a homogenous-goods and a differentiatedgoods sector. While there is a perfect labor market in the former sector, the latter is subject to search-and-matching frictions on the labor market. One of their basic results is that even though trade liberalization is welfare improving,

\footnotetext{
${ }^{2}$ Felbermayr and Prat (2007) introduce search-frictions in a model with heterogeneous firms à la Melitz (2003) in a closed economy. Felbermayr, Prat and Schmerer (2008) build on this theoretical model and extend it to a symmetric two-country model. As our model deals with two countries, we will cite Felbermayr, Prat and Schmerer (2008) in the subsequent, even though a lot of the key developments are indeed already presented in Felbermayr and Prat (2007).
} 
the distribution of wages becomes more unequal and the level of unemployment is higher in the trade equilibrium than in autarky. Although their model also incorporates workers with differing productivities, their approach is very different. In their model the differences among workers stem from an exogenously given distribution of ability which cannot be influenced by the workers. In our model the workers themselves invest in their human capital. Hence, the training decision is endogenous and changes in response to trade liberalization. Additionally, our model features sector- and skill-specific unemployment rates which allows for a richer picture of the distributional consequences of trade liberalization. Furthermore, we have got two differentiated sectors employing both unskilled and skilled labor and in both sectors search-and-matching frictions occur.

The last paper we want to mention is the one by Felbermayr, Prat and Schmerer (2008), who introduce search-and-matching unemployment into the Melitz (2003) framework, and find that trade liberalization has a positive effect on both wages and employment. As Felbermayr, Prat and Schmerer (2008) rely on a model with one sector, one factor and symmetric countries, there is no scope for comparative advantages. Additionally, the effects of trade liberalization cannot be differentiated according to various skill-classes, which is at the heart of this paper.

Concerning the interaction of mobility and selection the following recent developments are worth noting. Davidson, Martin, and Matusz (1999) assume that unemployed labor has no tie to any particular sector, since they have no sectorspecific skills. This implies that the unemployed workers are mobile between sectors, allowing to apply the Stolper-Samuelson theorem in order to evaluate the effects of trade liberalization. Hence, unemployed workers gain (loose) from trade liberalization if that particular type of labor is relatively abundant (scarce) in the country in question. The welfare effect for employed workers is driven by a weighted average of Stolper-Samuelson and Ricardo-Vinor effects. If turnover rates are high, then the Stolper-Samuelson effects dominate, while the RicardoVinor effects dominate if the turnover rates are low. The implication is that, in industries with high turnover rates, employed workers gain (lose) from trade liberalization if their type of labor is relatively abundant (scarce) in their country. However, in industries with low turnover, the welfare of employed workers is tied to the overall fortunes of the sector in which they are employed (see also Davidson and Matusz (2004)).

In order to capture a worker's possibilities to switch between sectors as well as to upgrade her skills, we allow for two kinds of worker-mobility between the labor markets. First, workers may switch between the two sectors, and, second, an unskilled worker may decide to acquire sector-specific skills to become a skilled worker. In line with other theoretical papers and empirical evidence ${ }^{3}$ we assume

\footnotetext{
${ }^{3}$ See Davidson and Matusz (2004, page 10); Anderson (2009); Greenaway, Upward and Wright (2000); and Elliott and Lindley (2006a,b).
} 
that only unemployed, unskilled workers can switch between the sectors. Typically, the acquisition of skills leads to a specialization in one sector/profession, making it harder and much more costly to switch between sectors. Hence, unskilled workers are less attached to sectors and therefore more mobile between the sectors. Restricting the mobility to unemployed workers seems to be realistic, as employed workers presumably do not have the time and may not see the need to switch the sector or to invest in training.

The main results of our model can be summarized as follows. Starting from autarky, trade liberalization leads to an increase in inter-industry trade between countries, where each country specializes in the sector where it has its comparative advantage. Comparative advantages stemming from lower training costs lead to specialization in the production of the skill-intensive good. In accordance with this specialization, workers migrate from the sector with the comparative disadvantage to the sector with the comparative advantage. Skilled labor looses in the import sector and gains in the export sector, both in terms of unemployment and wages.

The effects for unskilled labor are more equally distributed, because this factor is more mobile. In general, trade liberalization affects skilled workers more positively than unskilled workers in the advantaged sector but also more negatively than unskilled workers in the disadvantaged sector. If we take an aggregate perspective, we may state that the relatively abundant factor gains more from trade liberalization than the relatively scarce factor both in terms of real wages and employment levels.

Further decreases in trade costs lead to intra-industry trade between countries in both sectors. The effects of intra-industry trade occurring in both sectors can be very different from the effects of inter-industry trade, because it increases competition in both sectors, which leads to high average productivity in both sectors. This result has the potential to counteract some of the effects described above. For instance, wages of unskilled workers in the disadvantaged sectors begin to rise, implying that some of the unskilled workers who migrated to the advantaged sector due to inter-industry trade will migrate back to the other sector with the onset of intra-industry trade.

The remainder of the paper is structured as follows. Section 2 outlines the theoretical model. Section 3 derives numerical results from a calibration of our model, leading to predictions on the effect of trade liberalization for all variables. Section 4 compares our results to the results with perfect labor markets and without training possibilities, i.e., with the predictions obtained from the BRS model. In section 5 we do some sensitivity analysis, in order to show the qualitative robustness of our numerical results for various plausible parameter values. The last section concludes. 


\section{The Model}

Our model features two different factors of production (high-skilled and lowskilled labor) and two different sectors, one of them assumed to be skill-intensive. Furthermore, there is the possibility to export to a second country. Trade is subject to frictions, modeled in the type of iceberg transport costs. As in Melitz (2003) firms are heterogeneous with respect to their productivity, implying that the least efficient firms drop out of the market and only the most efficient firms take up export.

The labor market is subject to search-and-matching frictions in the style of Mortensen and Pissarides (1999) (see also Pissarides, 2000). This means that a firm has to pay a fixed cost to post a vacancy. This vacancy will be filled with a certain probability, which depends on the tightness of the labor market, defined as the ratio of vacancies to unemployed workers. We assume that the labor markets for each sector and for each factor are separated from each other, implying that we have four different labor markets. However, we allow for mobility of workers between sectors and allow unskilled workers to grade up their skills, hence, become skilled workers.

In the following we will first describe the production process, then the labor market and finally the entry- and export decision of a firm.

\section{$2.1 \quad$ Final goods}

Assume that there are two countries, a home country and a foreign country, denoted $H$ and $F$, respectively. In the following, we state the equations for the home country. Similar definitions apply for the foreign country. The utility of households is made up by the consumption of two goods which are produced by two different sectors, $i \in\{1,2\}$ :

$$
U^{H}=\left(C_{1}^{H}\right)^{\alpha_{1}}\left(C_{2}^{H}\right)^{\alpha_{2}}, \quad \alpha_{1}+\alpha_{2}=1,
$$

where $C_{i}^{H}$ is total consumption of final good $i$ in country $H$, and $\alpha_{i}$ denotes the income share spend on final good $i$.

Both consumption goods are aggregates of intermediate goods. The production function for the aggregate goods is: ${ }^{4}$

$$
Q_{i}^{H}=\left\{\left(M^{H}\right)^{-\frac{1}{\sigma}} \int_{\omega_{i}^{H} \in \Omega_{i}^{H}} q\left[\omega_{i}^{H}\right]^{\frac{\sigma-1}{\sigma}} d \omega_{i}^{H}\right\}^{\frac{\sigma}{\sigma-1}},
$$

where $\sigma>1$ denotes the elasticity of substitution between any two varieties of inputs, the measure of the set $\Omega_{i}^{H}$ is the mass $M^{H}$ of available intermediate inputs

\footnotetext{
${ }^{4}$ Whenever we use brackets this denotes arguments of functions, hence, $f[x]$ means $f$ as a function of $x$.
} 
in country $H$, each produced by a monopolistically competitive firm, and $q\left[\omega_{i}^{H}\right]$ denotes the quantity available of intermediate input $\omega_{i}^{H}$. The normalization $M^{H}$ assures that the rate of unemployment does not decrease with the size of the economy (see Blanchard and Giavazzi (2003), Egger and Kreickemeier (2008a,b) or Felbermayr, Prat and Schmerer (2008)). Note that aggregate production does not only have to cover aggregate consumption but also the various costs that accrue during the production process, so that $Q_{i}^{H} \leq C_{i}^{H}{ }^{5}$

The price index corresponding to the CES-aggregated good $Q_{i}^{H}$ is given by:

$$
P_{i}^{H}=\left(\frac{1}{M^{H}} \int_{\omega_{i}^{H} \in \Omega_{i}^{H}} p\left[\omega_{i}^{H}\right]^{1-\sigma} d \omega_{i}^{H}\right)^{\frac{1}{1-\sigma}},
$$

where $p\left[\omega_{i}^{H}\right]$ is the price of a variety $\omega_{i}^{H}$.

\section{$2.2 \quad$ Intermediate Goods}

Based on the utility function given in Equation (1) and the consumption index given in Equation (2), the inverse demand for each intermediate good can be derived as:

$$
p\left[\omega_{i}^{H}\right]=q\left[\omega_{i}^{H}\right]^{-\frac{1}{\sigma}}\left(P_{i}^{H}\right)^{\frac{\sigma-1}{\sigma}}\left(\frac{\alpha_{i} Y^{H}}{M^{H}}\right)^{\frac{1}{\sigma}},
$$

where $Y^{H}$ is total income of country $H$.

Firms have different productivity levels $\varphi\left[\omega_{i}^{H}\right]$. As every variety of intermediate input $\omega_{i}^{H}$ is produced by one firm, we may also index firms by $\varphi_{i}^{H}$. Input producers have to pay a sunk set-up cost $f$ in order to start production. Beside the domestic market, intermediate input producers can serve the foreign market via exports. However, entry into the export markets entails a fixed investment cost $f_{x}$. Further, serving customers abroad entails iceberg transportation costs $\tau \geq 1$. Hence, we may write the domestic and foreign inverse demand for the intermediate goods producer $\varphi_{i}^{H}$ as follows: ${ }^{6}$

$$
\begin{aligned}
& p_{d}\left[\varphi_{i}^{H}\right]=q_{d}\left[\varphi_{i}^{H}\right]^{-\frac{1}{\sigma}}\left(P_{i}^{H}\right)^{\frac{\sigma-1}{\sigma}}\left(\frac{\alpha_{i} Y^{H}}{M^{H}}\right)^{\frac{1}{\sigma}}, \\
& p_{x}\left[\varphi_{i}^{H}\right]=q_{x}\left[\varphi_{i}^{H}\right]^{-\frac{1}{\sigma}}\left(P_{i}^{F}\right)^{\frac{\sigma-1}{\sigma}}\left(\frac{\tau \alpha_{i} Y^{F}}{M^{F}}\right)^{\frac{1}{\sigma}} .
\end{aligned}
$$

If a firm decides to serve domestic and foreign markets, it allocates its output so as to maximize its total revenues. Equating marginal revenues across markets yields $p_{x}\left[\varphi_{i}^{H}\right]=\tau p_{d}\left[\varphi_{i}^{H}\right]$ (see Appendix A1).

\footnotetext{
${ }^{5}$ Like fixed costs of production and vacancy posting costs, which are all measured in terms of the aggregate good.

${ }^{6}$ Note that $p_{x}[$.$] is the cif price in the foreign market and q_{x}[$.$] is the quantity produced for$ the foreign market, including the iceberg transport costs.
} 
The production function of the intermediate-good producers is Cobb-Douglas:

$$
q\left[\varphi_{i}^{H}\right]=\varphi_{i}^{H} S\left[\varphi_{i}^{H}\right]^{\beta_{i}} L\left[\varphi_{i}^{H}\right]^{1-\beta_{i}}
$$

where $L\left[\varphi_{i}^{H}\right]\left(S\left[\varphi_{i}^{H}\right]\right)$ is the number of unskilled (skilled) workers employed by firm $\varphi_{i}^{H}$, and $\beta_{i}$ denotes the cost share of skilled workers.

Operating revenues of a firm in country $H$ with productivity $\varphi_{i}^{H}$ from sales on the domestic (foreign) market are equal to $R_{d}\left[\varphi_{i}^{H}\right]=p_{d}\left[\varphi_{i}^{H}\right] q_{d}\left[\varphi_{i}^{H}\right]\left(R_{x}\left[\varphi_{i}^{H}\right]=\right.$ $\left.p_{x}\left[\varphi_{i}^{H}\right] q_{x}\left[\varphi_{i}^{H}\right] / \tau\right)$. Thus, total revenue of this intermediate input producer $R\left[\varphi_{i}^{H}\right]$ is given by:

$$
\begin{aligned}
& R\left[\varphi_{i}^{H}\right]=q_{d}\left[\varphi_{i}^{H}\right]^{\frac{\sigma-1}{\sigma}}\left(P_{i}^{H}\right)^{\frac{\sigma-1}{\sigma}}\left(\frac{\alpha_{i} Y^{H}}{M^{H}}\right)^{\frac{1}{\sigma}} \\
& +I\left[\varphi_{i}^{H}\right] q_{x}\left[\varphi_{i}^{H}\right]^{\frac{\sigma-1}{\sigma}}\left(P_{i}^{F}\right)^{\frac{\sigma-1}{\sigma}}\left(\frac{\tau^{1-\sigma} \alpha_{i} Y^{F}}{M^{F}}\right)^{\frac{1}{\sigma}}
\end{aligned}
$$

where $I\left[\varphi_{i}^{H}\right]$ is an indicator function that takes value one when a firm in country $H$ with productivity $\varphi_{i}^{H}$ exports and zero otherwise.

\subsection{Vacancy Posting}

Firms are subject to labor market frictions of the matching type. They post a number of vacancies $v$ of which only a certain share $m[\theta]$ is filled. The number of matches depends negatively on labor market tightness $\theta=V / U$, where $V$ is the total number of vacancies posted on a specific labor market and $U$ is the number of unemployed workers on this labor market. Each period a worker faces a constant risk of death $d$. Additionally, with probability $\phi$ the match could be resolved due to exogenous reasons. Assuming independency of the death and exogenous split probability, the risk of loosing the worker is given by $\rho=\phi+d-\phi d$. Thus, the evolution of the stock of workers of a firm is governed by:

$$
\begin{aligned}
L_{i, t+1}^{H} & =(1-\rho) L_{i, t}^{H}+m\left[\theta_{L i}^{H}\right] v_{L i}^{H}, \\
S_{i, t+1}^{H} & =(1-\rho) S_{i, t}^{H}+m\left[\theta_{S i}^{H}\right] v_{S i}^{H} .
\end{aligned}
$$

Assuming that the costs of posting a vacancy are $c$ (measured in units of the final good), and that the firm is destroyed with an exogenous probability $\delta$, the value of a firm can then be written as:

$$
\begin{aligned}
J_{i, t}^{H}= & \frac{1}{1+r}\left(R\left[\varphi_{i}^{H}\right]-w_{L i}^{H} L\left[\varphi_{i}^{H}\right]-w_{S i}^{H} S\left[\varphi_{i}^{H}\right]-f P_{i}^{H}\right. \\
& \left.-v_{L i}^{H} c P_{i}^{H}-v_{S i}^{H} c P_{i}^{H}-I\left[\varphi_{i}^{H}\right] f_{x} P_{i}^{H}+(1-\delta) J_{i, t+1}^{H}\right),
\end{aligned}
$$

where $r$ denotes the interest rate, and $w_{L i}^{H}\left(w_{S i}^{H}\right)$ is the unskilled (skilled) labor wage rate in industry $i$ in country $H$. 
The firm maximizes its value by choosing the number of vacancies posted subject to its demand, production function and evolution of employment, i.e. Equations (4), (6) and (8), respectively. The first order conditions are:

$$
\begin{aligned}
c P_{i}^{H} & =m\left[\theta_{L i}^{H}\right](1-\delta) \lambda_{L i, t+1}^{H}, \\
c P_{i}^{H} & =m\left[\theta_{S i}^{H}\right](1-\delta) \lambda_{S i, t+1}^{H},
\end{aligned}
$$

where we have marginal costs on the left-hand side, marginal revenues on the right-hand side and $\lambda_{L i, t+1}^{H}\left(\lambda_{S i, t+1}^{H}\right)$ is the shadow value of employment of unskilled (skilled) labor in period $t+1$. These shadow values can be determined using the envelope condition. Additionally employing the steady-state condition $\left(J_{t}=J_{t+1}\right)$, Equation (10) can be written as (see Appendix A2):

$$
\begin{aligned}
& \frac{\partial R\left[\varphi_{i}^{H}\right]}{\partial L_{i}^{H}}=\frac{c P_{i}^{H}}{m\left[\theta_{L i}^{H}\right]} \frac{s+r}{1-\delta}+w_{L i}^{H}+\frac{\partial w_{L i}^{H}}{\partial L_{i}^{H}} L\left[\varphi_{i}^{H}\right], \\
& \frac{\partial R\left[\varphi_{i}^{H}\right]}{\partial S_{i}^{H}}=\frac{c P_{i}^{H}}{m\left[\theta_{S i}^{H}\right]} \frac{s+r}{1-\delta}+w_{S i}^{H}+\frac{\partial w_{S i}^{H}}{\partial S_{i}^{H}} S\left[\varphi_{i}^{H}\right],
\end{aligned}
$$

with $s=\rho+\delta-\rho \delta$ being the rate of job destruction, assuming independency of the risk of loosing a worker and the exogenous probability of firm destruction.

\subsection{Wages}

We assume that every worker individualistically bargains with her employer. As in Stole and Zwiebel (1996) every worker is treated as the marginal worker, i.e. as the last worker employed by the firm. The outcome of the bargaining process satisfies the following "surplus-splitting" rule:

$$
\begin{aligned}
(1-\mu)\left(E_{L}\left[\varphi_{i}^{H}\right]-U_{L i}^{H}\right) & =\mu \frac{\partial J\left[\varphi_{i}^{H}\right]}{\partial L_{i}^{H}}, \\
(1-\mu)\left(E_{S}\left[\varphi_{i}^{H}\right]-U_{S i}^{H}\right) & =\mu \frac{\partial J\left[\varphi_{i}^{H}\right]}{\partial S_{i}^{H}},
\end{aligned}
$$

where $E_{L}\left[\varphi_{i}^{H}\right]\left(E_{S}\left[\varphi_{i}^{H}\right]\right)$ denotes the asset value of an unskilled (skilled) worker employed at a firm with productivity $\varphi_{i}^{H}$ in industry $i$, while $U_{L i}^{H}\left(U_{S i}^{H}\right)$ is the value of an unskilled (skilled) unemployed worker. $\mu$ measures the bargaining power of a worker and belongs to $[0,1]$.

Following the same procedure as Felbermayr, Prat and Schmerer (2008) we get the job-creation conditions (see Appendix A3):

$$
\begin{aligned}
w_{L i}^{H} & =(1-\beta) p_{d}\left[\varphi_{i}^{H}\right] \varphi_{i}^{H}\left(\frac{S\left[\varphi_{i}^{H}\right]}{L\left[\varphi_{i}^{H}\right]}\right)^{\beta} \frac{\sigma-1}{\sigma+\beta_{i} \mu-\mu-\beta_{i} \sigma \mu}-\frac{c P_{i}^{H}}{m\left[\theta_{L i}^{H}\right.} \frac{s+r}{1-\delta} \\
w_{S i}^{H} & =\beta p_{d}\left[\varphi_{i}^{H}\right] \varphi_{i}^{H}\left(\frac{S\left[\varphi_{i}^{H}\right]}{L\left[\varphi_{i}^{H}\right]}\right)^{\beta-1} \frac{\sigma-1}{\sigma-\beta_{i} \mu+\beta_{i} \sigma \mu-\sigma \mu}-\frac{c P_{i}^{H}}{m\left[\theta_{S i}^{H}\right]} \frac{s+r}{1-\delta} .
\end{aligned}
$$


The wage curves are given by:

$$
\begin{aligned}
& w_{L i}^{H}=(r+d) U_{L i}^{H}+\frac{\mu}{1-\mu} \frac{r+s}{1-\delta} \frac{c P_{i}^{H}}{m\left[\theta_{L i}^{H}\right]}, \\
& w_{S i}^{H}=(r+d) U_{S i}^{H}+\frac{\mu}{1-\mu} \frac{r+s}{1-\delta} \frac{c P_{i}^{H}}{m\left[\theta_{S i}^{H}\right]} .
\end{aligned}
$$

Substituting out the value of unemployment the wage curves become:

$$
\begin{aligned}
& w_{L i}^{H}=b+\frac{\mu}{1-\mu}\left(\frac{r+s}{1-\delta} \frac{c P_{i}^{H}}{m\left[\theta_{L i}^{H}\right]}+\frac{c P_{i}^{H} \theta_{L i}^{H}}{1-\delta}\right), \\
& w_{S i}^{H}=b+\frac{\mu}{1-\mu}\left(\frac{r+s}{1-\delta} \frac{c P_{i}^{H}}{m\left[\theta_{S i}^{H}\right]}+\frac{c P_{i}^{H} \theta_{S i}^{H}}{1-\delta}\right) .
\end{aligned}
$$

The equilibrium on the labor market is jointly determined by the wage curve and the job-creation condition which pin down the wage and the tightness of the labor market. As in Stole and Zwiebel (1996) and Felbermayr, Prat and Schmerer (2008), the assumption that a firm is bargaining with the marginal worker implies that the wage of each worker is driven down to her outside option. This in turn implies that each firm is paying the same wage, irrespective of its productivity level. In equilibrium, each firm employs as many workers as are necessary to ensure that the marginal value of the last employed worker of the firm is equal to the wage.

\subsection{Firm Entry and Exit}

There is an infinite number of potential firms which can enter the market after having paid a fixed and sunk entry cost $f_{E}$, measured in terms of the final consumption good of the sector the firm wants to enter. Once a firm has entered into industry $i$ it will draw its productivity $\varphi_{i}^{H}$ from a known distribution $g\left[\varphi_{i}^{H}\right]$. The productivity stays the same as long as the firm exists. Only firms which draw a $\varphi_{i}^{H}$ favorable enough to make non-negative profits will start production. To describe this entry-decision let us define the per-period profit of a firm as:

$$
\begin{aligned}
\pi_{d}\left[\varphi_{i}^{H}\right] & =p_{d}\left[\varphi_{i}^{H}\right] q_{d}\left[\varphi_{i}^{H}\right]-w_{L i}^{H} L\left[\varphi_{i}^{H}\right]-w_{S i}^{H} S\left[\varphi_{i}^{H}\right] \\
& -f P_{i}^{H}-\frac{\rho c P_{i}^{H} L\left[\varphi_{i}^{H}\right]}{m\left[\theta_{L i}^{H}\right]}-\frac{\rho c P_{i}^{H} S\left[\varphi_{i}^{H}\right]}{m\left[\theta_{S i}^{H}\right]}
\end{aligned}
$$

which is revenue minus wage payments, fixed costs and search costs necessary to replace the fired workers. ${ }^{7}$ A firm will decide to start up production whenever its

\footnotetext{
${ }^{7}$ Remember that $\rho$ is the separation rate and that $m[\theta]$ is the share of vacancies filled. Hence, from Equation (8) and employing the steady-state condition $L_{i, t+1}^{H}=L_{i, t}^{H}=L_{i}^{H}$, it follows that $v_{L i}^{H}=\left(\rho L_{i}^{H}\right) / m\left[\theta_{L i}^{H}\right]$.
} 
productivity exceeds a certain threshold-value $\varphi_{i}^{* H}$, defined by:

$$
(1-\delta) \frac{\pi_{d}\left[\varphi_{i d}^{* H}\right]}{r+\delta}=\frac{c P_{i}^{H} L\left[\varphi_{i d}^{* H}\right]}{m\left[\theta_{L i}^{H}\right]}+\frac{c P_{i}^{H} S\left[\varphi_{i d}^{* H}\right]}{m\left[\theta_{S i}^{H}\right]}+f P_{i}^{H},
$$

where $L\left[\varphi_{i d}^{* H}\right]$ and $S\left[\varphi_{i d}^{* H}\right]$ are the unskilled and skilled labor inputs needed for domestic production in industry $i$ of the firm with productivity $\varphi_{i d}^{* H}$. At the beginning of its existence the firm has to "invest" in its stock of workers, i.e., all of the workers have to be hired newly. ${ }^{8}$ The discounted value of future profits has to be large enough so that a firm wants to undertake this upfront investment. Otherwise, the firm immediately exits. Equivalently to Equation (17), we can determine the export threshold as:

$$
(1-\delta) \frac{\pi_{x}\left[\varphi_{i x}^{* H}\right]}{r+\delta}=\frac{c P_{i}^{H} L\left[\varphi_{i x}^{* H}\right]}{m\left[\theta_{L i}^{H}\right]}+\frac{c P_{i}^{H} S\left[\varphi_{i x}^{* H}\right]}{m\left[\theta_{S i}^{H}\right]}+f_{x} P_{i}^{H},
$$

where $L\left[\varphi_{i x}^{* H}\right]$ and $S\left[\varphi_{i x}^{* H}\right]$ are the additional unskilled and skilled labor inputs needed to produce for the foreign market for a firm in industry $i$ with productivity $\varphi_{i x}^{* H} . \pi_{x}\left[\varphi_{i x}^{* H}\right]$ is the additional profit from serving the export market, defined similarly as the profit from serving the local market (see Equation (16)). ${ }^{9}$ The profits from serving the foreign market have to be large enough to justify the extra fixed costs $f_{x}$. Empirical evidence strongly supports selection into export markets. ${ }^{10}$ Hence, we focus on parameter values where only the most productive firms export and therefore $\varphi_{i x}^{* H}>\varphi_{i d}^{* H}$.

Following Melitz (2003), we define the average productivity of a domestic firm serving the domestic (foreign) market as:

$$
\begin{aligned}
& \tilde{\varphi}_{i d}^{H}\left[\varphi_{i d}^{* H}\right]=\left(\frac{1}{1-G\left[\varphi_{i d}^{* H}\right]} \int_{\varphi_{i d}^{* H}}^{\infty}\left(\varphi_{i}^{H}\right)^{\sigma-1} g\left[\varphi_{i}^{H}\right] d \varphi_{i}^{H}\right)^{1 /(\sigma-1)}, \\
& \tilde{\varphi}_{i x}^{H}\left[\varphi_{i x}^{* H}\right]=\left(\frac{1}{1-G\left[\varphi_{i x}^{* H}\right]} \int_{\varphi_{i x}^{* H}}^{\infty}\left(\varphi_{i}^{H}\right)^{\sigma-1} g\left[\varphi_{i}^{H}\right] d \varphi_{i}^{H}\right)^{1 /(\sigma-1)} .
\end{aligned}
$$

Based on these definitions we can write down the free entry condition as:

$$
\begin{aligned}
& f_{E} P_{i}^{H}=\left(1-G\left[\varphi_{i d}^{* H}\right]\right)\left((1-\delta) \frac{\pi_{d}\left[\tilde{\varphi}_{i d}^{H}\right]}{r+\delta}-\frac{c P_{i}^{H} L\left[\tilde{\varphi}_{i d}^{H}\right]}{m\left[\theta_{L i}^{H}\right]}-\frac{c P_{i}^{H} S\left[\tilde{\varphi}_{i d}^{H}\right]}{m\left[\theta_{S i}^{H}\right]}-f P_{i}^{H}\right) \\
& +\left(1-G\left[\varphi_{i x}^{* H}\right]\right)\left((1-\delta) \frac{\pi_{x}\left[\tilde{\varphi}_{i x}^{H}\right]}{r+\delta}-\frac{c P_{i}^{H} L\left[\tilde{\varphi}_{i x}^{H}\right]}{m\left[\theta_{L i}^{H}\right]}-\frac{c P_{i}^{H} S\left[\tilde{\varphi}_{i x}^{H}\right]}{m\left[\theta_{S i}^{H}\right]}-f_{x} P_{i}^{H}\right),
\end{aligned}
$$

${ }^{8}$ Note that due to the linearity of adjustment costs the work-force immediately jumps to the optimal value.

${ }^{9}$ In Appendix A4 we derive the relationship between the zero-profit productivity cut-off and the exporting productivity cut-off.

${ }^{10}$ For empirical evidence on selection into the export markets, see Bernard and Jensen (1995, 1999, 2004), Roberts and Tybout (1997), and Clerides, Lach and Tybout (1998). 
where we have the costs of entering a market, measured in units of the final good, on the left-hand side and the expected profits on the right-hand side. The profits of the firm are not yet known at the time of the entry-decision because the productivity level is unknown. With probability $1-G\left[\varphi_{i d}^{* H}\right]$ the productivity will be high enough to make production profitable. With probability $1-G\left[\varphi_{i x}^{* H}\right]$ the productivity will be high enough so that even exporting is profitable. The terms in paranthesis indicate how much a firm will earn in these cases.

Equality in Equation (21) is assured by the entry of new firms. As long as average profits exceed the entry cost, new firms will enter the market, leading to increased competition and thereby driving down profits until they have reached the entry cost (and vice versa if profits are too low).

The ex ante probability of successful entry into industry $i$ in country $H$ is $\left(1-G\left[\varphi_{i d}^{* H}\right]\right)$, whereas the ex ante probability of exporting conditional on successful entry is:

$$
\chi_{i}^{H}=\frac{1-G\left[\varphi_{i x}^{* H}\right]}{1-G\left[\varphi_{i d}^{* H}\right]} .
$$

Given the probability of exporting, we can determine the mass of available intermediate inputs as $M^{H}=M_{i}^{H}+\chi_{i}^{F} M_{i}^{F}$.

\subsection{Unemployment}

As already mentioned above, we assume the existence of four separate labor markets: one for each sector and skill-class. Each labor market is described by a Cobb-Douglas matching function:

$$
\begin{aligned}
m\left[\theta_{L i}^{H}\right] & =\bar{m}\left(\theta_{L i}^{H}\right)^{-\gamma}, \\
m\left[\theta_{S i}^{H}\right] & =\bar{m}\left(\theta_{S i}^{H}\right)^{-\gamma},
\end{aligned}
$$

where the parameter $\bar{m}$ measures the efficiency of the labor market, while $\gamma$ is the elasticity of the matching function. The matching function gives the probability that a vacancy is filled in dependence of $\theta$, the tightness of the labor market. In turn, the probability that an unskilled (skilled) worker finds a job in industry $i$ in country $H$ can be written as $\theta_{L i}^{H} m\left[\theta_{L i}^{H}\right]\left(\theta_{S i}^{H} m\left[\theta_{S i}^{H}\right]\right)$. Furthermore, we assume that workers are born at the same rate as the risk of death $d$. Newborn workers have the same distribution of training costs as the older population and can immediately acquire the specific skills in order to get skilled workers in one of the two sectors. Thus, in steady state the number of skilled and unskilled workers in each sector is stationary and independent of the risk of death. ${ }^{11}$ In that case, it is irrelevant why a job has been destroyed (whether the worker or firm died or

\footnotetext{
${ }^{11}$ The reason why we use this formulation with the risk of death is to give an economy the opportunity to adjust from one steady state to the other even when this is accompanied by a reduction in the number of skilled workers in one or both sectors.
} 
whether just the match was destroyed). All that matters is the rate of overall job destruction $s$ and, thus, the equilibrium rate of unemployment is given by:

$$
\begin{aligned}
u_{L i}^{H} & =\frac{s}{s+\theta_{L i}^{H} m\left[\theta_{L i}^{H}\right]}, \\
u_{S i}^{H} & =\frac{s}{s+\theta_{S i}^{H} m\left[\theta_{S i}^{H}\right]} .
\end{aligned}
$$

Finally, the mass of firms has to adjust so that the labor market clears:

$$
\begin{aligned}
M_{i}^{H}\left(L\left[\tilde{\varphi}_{i d}^{H}\right]+\chi_{i}^{H} L\left[\tilde{\varphi}_{i x}^{H}\right]\right) & =\left(1-u_{L i}^{H}\right) \hat{L}_{i}^{H}, \\
M_{i}^{H}\left(S\left[\tilde{\varphi}_{i d}^{H}\right]+\chi_{i}^{H} S\left[\tilde{\varphi}_{i x}^{H}\right]\right) & =\left(1-u_{S i}^{H}\right) \hat{S}_{i}^{H},
\end{aligned}
$$

where $\hat{L}_{i}^{H}\left(\hat{S}_{i}^{H}\right)$ is the total number of unskilled (skilled) workers in sector $i$ in country $H$. The left-hand side shows the demand for labor, given by the sum of the demand of all domestic firms for domestic and export production. The right hand side of Equation (25) gives the number of employed workers (from the supply-side). Note that the total number of unskilled and skilled workers of both sectors has to add-up to the exogenously given total number of people, i.e., $N^{H}=\sum_{i}\left(\hat{L}_{i}^{H}+\hat{S}_{i}^{H}\right)$.

\subsection{Mobility}

We allow for two kinds of worker-mobility between the labor markets. On the one hand a worker might want to switch between the two sectors, on the other hand an unskilled worker might want to train to become a skilled worker. ${ }^{12}$

Considering the movement between the sectors we assume that only unemployed, unskilled workers can switch between the sectors. Typically, the acquisition of skills implies a specialization in one field, which clearly restricts the mobility between one sector and the other. On the other hand, unskilled workers are much less specialized and thus more mobile between the sectors. This assumption is very much in line with empirical evidence. Greenaway, Upward and Wright (2000) as well as Elliott and Lindley (2006b) find that unskilled workers are much more mobile than skilled workers. Elliott and Lindley (2006a) confirm this result and argue that this is due to their significant investments in specific human capital. One exception is Greenaway, Upward and Wright (2002) who get the result that skilled workers have higher flow rates. However, their analysis is restricted to net-flows of workers, while gross-flows are used in the other papers. Migration costs likely depend on the total number of worker-flows, hence grossflows seem to be the more sensible measure for mobility costs (see Greenaway, Upward and Wright, 2000). ${ }^{13}$

\footnotetext{
${ }^{12}$ Due to our assumption of a positive death rate of people, it may also be the case that the number of skilled workers between different steady-states shrinks.

${ }^{13}$ Migration costs occur at the individual level. Hence, net-flows would underestimate migration costs, especially if two-way migration flows between two countries are of similar magnitude.
} 
Furthermore, an employed worker is not likely to have the time and, maybe even more importantly, does not see the need to switch the sector. Therefore, we restrict the mobility between sectors to unemployed, unskilled workers. All this is in line with the reasoning of Davidson and Matusz (2004, page 10).

We assume that in the long-run there are no mobility costs between the two sectors. Hence the value of an unskilled, unemployed worker in both sectors needs to be equalized in the home as well as in the foreign country:

$$
\begin{aligned}
U_{L 1}^{H} & =U_{L 2}^{H}, \\
U_{L 1}^{F} & =U_{L 2}^{F} .
\end{aligned}
$$

For the same reasoning as above, we assume that only an unemployed worker has the time and motivation to invest in her human capital. After paying a fixed training cost an unemployed, unskilled worker can become an unemployed, skilled worker in the same sector. To get an interior solution we assume that workers are heterogeneous with respect to training costs. Since the workers with the highest training ability will train first, this implies that training costs are increasing in the number of skilled workers. For simplicity we assume a linear relationship, hence training costs are given by:

$$
\begin{aligned}
\kappa\left[\hat{S}_{i}^{H}\right] & =\bar{\kappa}^{H} \hat{S}_{i}^{H}, \\
\kappa\left[\hat{S}_{i}^{F}\right] & =\bar{\kappa}^{F} \hat{S}_{i}^{F},
\end{aligned}
$$

where $\bar{\kappa}^{H}\left(\bar{\kappa}^{F}\right)$ are country specific constants, implying $\partial \kappa\left[\hat{S}_{i}^{H}\right] / \partial \hat{S}_{i}^{H}>0$ as well as $\partial \kappa\left[\hat{S}_{i}^{F}\right] / \partial \hat{S}_{i}^{F}>0 .{ }^{14}$

Then the number of skilled worker is endogenously determined by:

$$
\begin{aligned}
U_{S i}^{H}-U_{L i}^{H} & =\kappa\left[\hat{S}_{i}^{H}\right], \\
U_{S i}^{F}-U_{L i}^{F} & =\kappa\left[\hat{S}_{i}^{F}\right] .
\end{aligned}
$$

The marginal worker in country $H(F)$ is just indifferent between training and staying unskilled because the gain from training, $U_{S i}^{H}-U_{L i}^{H}\left(U_{S i}^{F}-U_{L i}^{F}\right)$, is exactly equal to the costs of training, $\kappa\left[\hat{S}_{i}^{H}\right]\left(\kappa\left[\hat{S}_{i}^{F}\right]\right)$. Note that Equation (28) is a steady-state equilibrium condition, implying that in the movement from one steady state to the other it is also possible that some skilled workers decide to "degrade" their skills and become unskilled workers.

Figure 1 summarizes our structure concerning the mobility of workers and gives the indifference conditions for unemployed, unskilled workers to switch sectors, as well as for unemployed, unskilled workers to invest in her human capital. ${ }^{15}$

\footnotetext{
${ }^{14} \bar{\kappa}^{H}\left(\bar{\kappa}^{F}\right)$ are used to calibrate the shares of skilled workers in the home (foreign) country.

${ }^{15}$ Given our constraint that the workforce is fixed $\left(N^{H}=\sum_{i}\left(\hat{L}_{i}^{H}+\hat{S}_{i}^{H}\right)\right)$ we can only allow for three flow-conditions (three more equations). Allowing skilled unemployed workers to switch sectors, too, would yield us five equations with four unknowns and thus the model would not be solvable.
} 
Sector 1

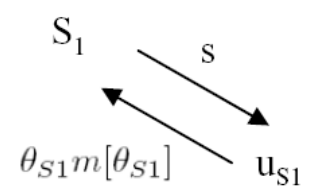

Sector 2

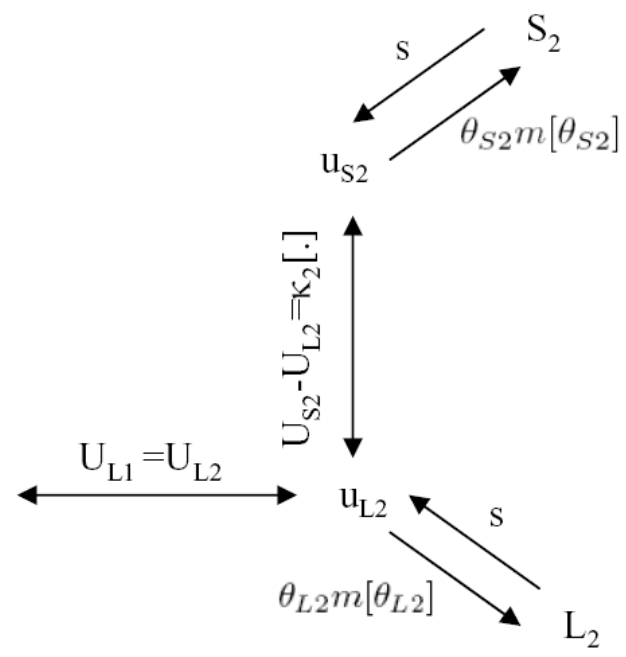

Figure 1: Mobility Assumptions of Workers

It also illustrates the four separate labor markets and the flows on these markets between unemployment and employment.

The introduction of the possibility to train and upgrade skills in addition to the possibility to switch sectors gives rise to new insights concerning the effects of trade liberalization on training, and hence, the skill-composition of the workforce. As mentioned in the introduction, the share of the population attaining the tertiary level of education varies substantially between countries. Even though the distributional consequences of trade liberalization are one of the core issues in international trade, the workhorse models in trade, like the Heckscher-Ohlin, the Ricardo-Viner model as well as new trade theory models, assume that the skill composition of the workforce is unaffected in the pace of trade liberalization. We want to challenge this view, and explicitly allow for an endogenous skill composition. It will turn out that the change of the skill composition between sectors depends strongly on the type of trade, i.e., whether trade is of the inter-industry or of the intra-industry type.

\section{$3 \quad$ Numerical Results}

\subsection{Calibration}

In order to highlight the interaction of comparative advantages and the endogenous selection of workers to sectors and skill-classes, we assume that sector one 
is skill-intensive relative to sector two in both countries $\left(\beta_{1}=0.8\right.$ and $\left.\beta_{2}=0.2\right)$ and that consumers in both countries spend a larger share of their income on final goods of sector one $(\alpha=0.7)$. Further, the home country is assumed to have better training opportunities, i.e. $\bar{\kappa}_{i}^{H}<\bar{\kappa}_{i}^{F}$. Specifically, we choose the training costs such that the home country has $50 \%$ skilled workers, while the foreign country has only $20 \%$ skilled workers. This is in line with data from the OECD (2007), showing that the share of the population attaining the tertiary level of education can range from $20 \%$ for Slovenia to $54 \%$ for Canada. ${ }^{16}$

The model is calibrated for moderate trade costs $\tau=1.3$. The elasticity of substitution $\sigma$ is set to 3.8. Concerning the ex ante firm productivity we assume a Pareto distribution, given by:

$$
g\left[\varphi_{i}^{H}\right]=a k^{a}\left(\varphi_{i}^{H}\right)^{-(a+1)},
$$

where $k$ is the minimum value of productivity $\left(\varphi_{i}^{H} \geq k\right)$, and $a>0$ is the shape parameter that determines the skewness of the Pareto distribution. We set $k=0.2$ and $a=3.4$ for both countries and both industries. Both values are the same as in BRS and Felbermayr, Prat and Schmerer (2008). As BRS we choose fixed entry costs and fixed production costs to be $f_{E}=2$ and $f=0.1$. The fixed costs of serving the foreign market are set to $f_{x}=0.193$. This implies that approximately $22 \%$ of firms in sector one of the home country export, which is in line with Bernard, Eaton, Jensen and Kortum (2003).

The probability of firm-breakdown is set equal to $\delta=0.11$, implying an annual gross rate of firm turnover of $22 \%$ as suggested by Bartelsmann, Haltiwanger and Scarpetta (2004). Based on the estimates of Shimer (2005) we choose the annual rate of job destruction to be $s=0.41$. This implies that the rate of match separation (including death and idiosyncratic shocks but not firm-breakdown) is equal to $\rho=0.3$.

Following Petrongolo and Pissarides (2001) the elasticity of the matching function is set equal to 0.5. While Hall (2005) finds a labor market tightness of 0.5, Shimer (2005) gets a monthly job-finding rate of 0.45. From Equation (23) follows that the monthly job-filling rate has to be 0.9 , which in turn implies an efficiency parameter for the matching function of $\bar{m}=7.6$.

We set the discount rate to $r=0.04$, implying a yearly interest rate of $4 \%$. The replacement rate of unemployment benefits, $b$, is equal to 0.4 , which implies that workers receive $40 \%$ of their wage when becoming unemployed. Both values are well in line with empirical facts and similar to BRS and Felbermayr, Prat and Schmerer (2008). Considering the parameter for the bargaining power of workers, we follow the common practice and set it equal to the elasticity of the matching

\footnotetext{
${ }^{16}$ In the sensitivity analysis we show that choosing more equal countries does not change the qualitative results of the model. Note, that we calibrate the model for unskilled labor in sector one in the home country. We then use the same parameters for all other markets, except for the differences just noted.
} 
Table 1: Calibration of Parameter Values

\begin{tabular}{||l||l|l|l||}
\hline Parameter & Description & Value & Source \\
\hline \hline$r$ & Discount rate & 0.04 & $4 \%$ annual discount rate \\
\hline$\sigma$ & Elasticity of Substitution & 3.8 & BRS \\
\hline$\beta_{1}$ & Skilled labor cost share in sector one & 0.8 & Similar to BRS \\
\hline$\beta_{2}$ & Skilled labor cost share in sector two & 0.2 & Similar to BRS \\
\hline$\alpha$ & Industry one goods income share & 0.7 & Reflects higher income share sector \\
\hline$f_{E}$ & Fixed entry cost & 2 & BRS \\
\hline$f$ & Fixed cost of production & 0.1 & BRS \\
\hline$f_{x}$ & Fixed foreign market access costs & 0.193 & Bernard, Eaton, Jensen and Kortum $(2003)$ \\
\hline$\delta$ & Rate of firm exit & 0.11 & Bartelsmann, Haltiwanger and Scarpetta $(2004)$ \\
\hline$k$ & Minimum value of productivity & 0.2 & BRS \\
\hline$a$ & Shape of Pareto Distribution & 3.4 & BRS \\
\hline$b$ & Unemployment benefits & $0.4 \times$ wage & 40\% effective replacement rate \\
\hline$\mu$ & Bargaining power & 0.5 & Hosios (1990) \\
\hline$\gamma$ & Elasticity of matching function & 0.5 & Petrongolo and Pissarides $(2001)$ \\
\hline $\bar{m}$ & Efficiency of matching function & 7.6 & Shimer $(2005)$ and Hall $(2005)$ \\
\hline$c$ & Cost of posting a vacancy & 0.134 & To match $\theta=0.5$ (Hall, 2005) \\
\hline$\rho$ & Monthly job separation rate & 0.3 & Shimer $(2005)$ \\
\hline$k_{i}^{H}$ & Training costs in country $H$ & $0.0105 \times P_{i}^{H}$ & Implies 50\% skilled workers \\
\hline$k_{i}^{F}$ & Training costs in country $F$ & $0.076 \times P_{i}^{F}$ & Implies 20\% skilled workers \\
\hline$\tau$ & Iceberg trade costs & 1.3 & Ghironi and Melitz (2005) \\
\hline$N^{H}=N^{F}$ & Size of population & 1000 & Size normalization \\
\hline$P_{1}^{H}$ & Numéraire & 1 & Normalization \\
\hline
\end{tabular}


function. Specifically, we set $\mu=0.5$. The equality of the bargaining power and matching function elasticity is known as the "Hosios condition" (Hosios, 1990). Note, however, that in the present model this condition is not sufficient to ensure an efficient allocation due to the over-hiring externality (see also Felbermayr, Prat, and Schmerer (2008)). ${ }^{17}$ Finally, we choose the costs of posting a vacancy such that the resulting labor market tightness for unskilled workers in sector one matches the value of 0.5 (see Hall (2005) for empirical evidence). This implies a value of $c=0.134$.

\subsection{The Effects of Trade Liberalization}

In this section we illustrate the effects of trade liberalization for our baseline economy. We start out with a $\tau$ equal to 5 - which implies that there is almost no trade at all and hence we refer to it as autarky in the following - and lower it until it reaches 1 , implying free trade. The most important effects of trade liberalization are summarized in the form of results.

Due to the differences in training costs between the countries, even under autarky the two countries do not produce the same sectoral mix of products. Lower training costs imply that it pays off for more workers to acquire the skills necessary to perform a skilled labor job. This leads to an abundance of skilled workers in the country with lower training costs. Hence, even in autarky the home country produces more goods in sector one, whereas the foreign country produces more goods in sector two.

In the following we concentrate on the characterization of the skill-abundant home country. First, note that wages for skilled labor are ensured to be larger than wages for unskilled labor due to the training possibilities of unskilled workers. As we assume that sectors differ only with respect to their factor intensities (specifically, that sector one is more skilled labor intensive than sector two), this implies that prices for a variety in sector one are higher. Higher prices lead to a higher level of wages due to the wage negotiations. Hence, both, skilled and unskilled workers get higher wages in sector one. Given the full mobility of unskilled (unemployed) workers, this leads to movements of unskilled workers to sector one, until the value of an unemployed unskilled worker is equalized between sectors. Due to these migration flows, unemployment is higher in sector one. ${ }^{18}$ For the less mobile factor, skilled labor, things look a bit different. This factor is generally better off in the sector with the comparative advantage. The specialization pattern is summarized in Result 1:

\footnotetext{
${ }^{17}$ We take care in all our simulations that the condition given in Appendix A5 is satisfied. In the sensitivity analysis we demonstrate that this does not affect our qualitative results.

${ }^{18}$ If unemployment did not rise, the value of an unemployed unskilled worker would be lower in sector two, causing migration from sector two to sector one, thereby driving up unemployment in sector one (and lowering unemployment in sector two), until the value of an unemployed unskilled worker is the same in both sectors.
} 


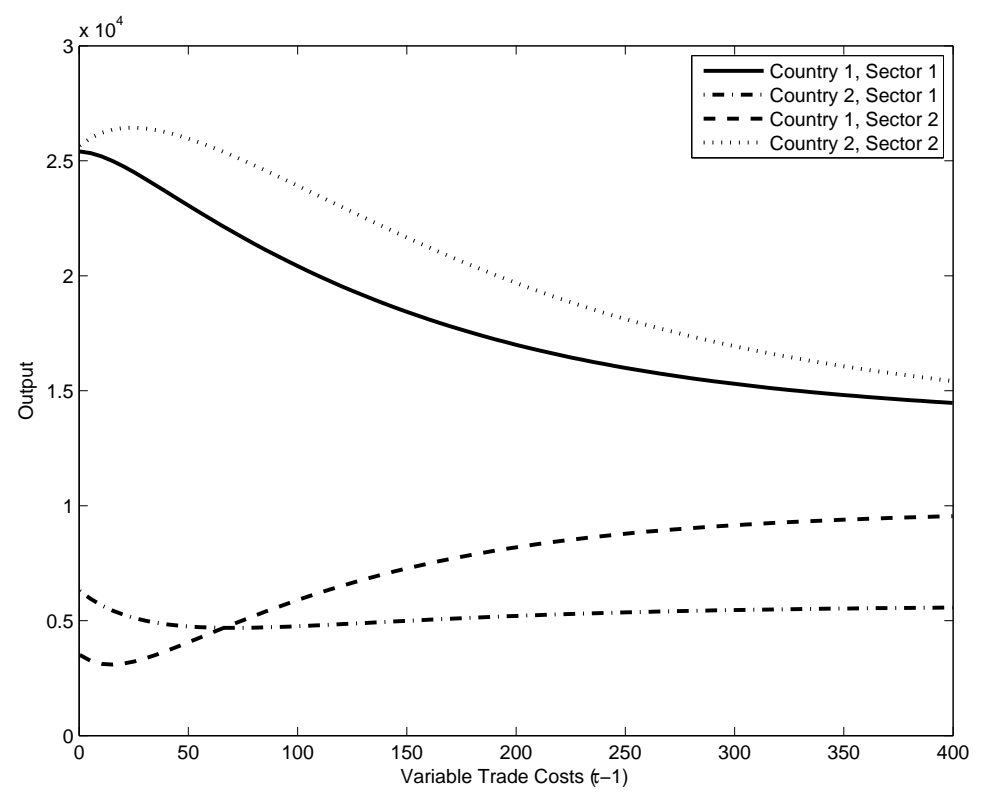

Figure 2: Production per Sector

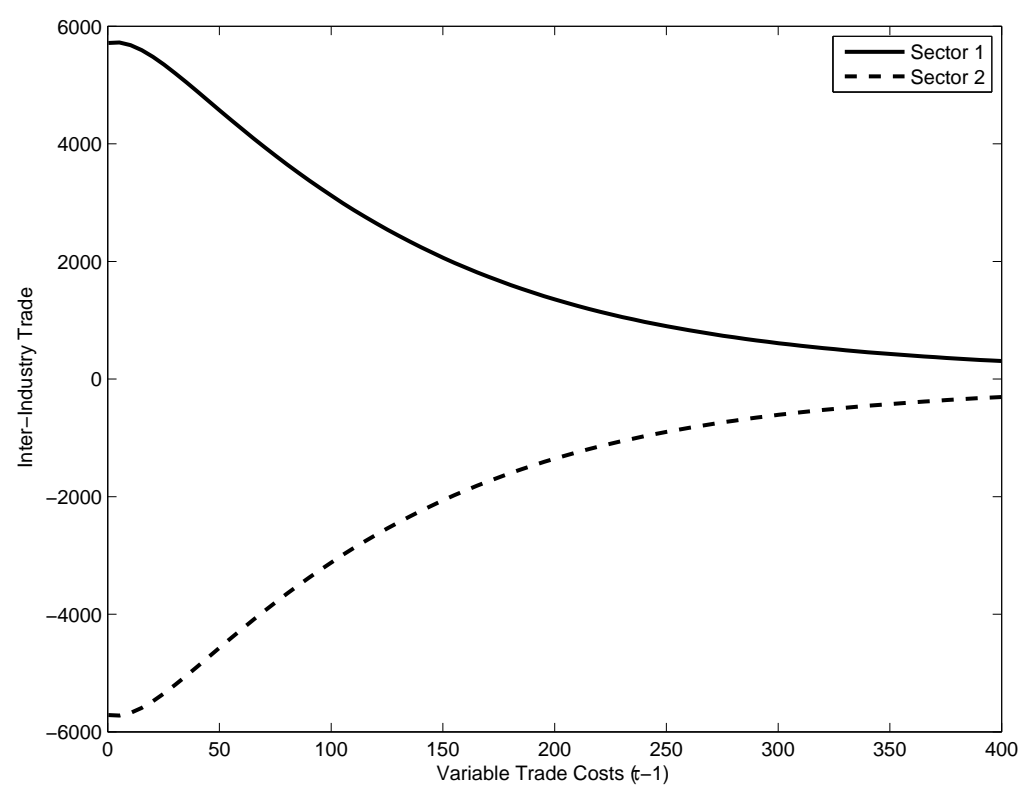

Figure 3: Inter-industry Trade 


\section{Result 1 [Specialization]:}

As trade costs decrease, inter-industry trade increases and each country specializes in the sector where it has its comparative advantage, i.e. the country with lower training costs specializes in the production of the skill-intensive good and vice versa.

Let us study the effects of trade liberalization on the most important variables in turn. Going from right to left in Figure 2, we see that each country specializes increasingly in the sector with its comparative advantage. Hence, lower trade costs lead to stronger specialization, aggravating the production structure which is already present in autarky. Specifically, the home country increases production in sector one and decreases production in sector two. At the same time the home country becomes a net-exporter of goods from sector one and a net-importer of goods from sector two. Inter-industry trade increases considerably when trade costs are lowered (see Figure 3). ${ }^{19}$

The increased specialization of countries at lower trade costs is due to the increased possibility to exchange goods between countries, leading to a more efficient allocation of factors, which is at the heart of the "gains from trade". This increased specialization induces reallocation of workers between sectors, similar to the traditional Heckscher-Ohlin model. However, additionally to this traditional reallocation of workers, there is an endogenous response of the composition of the skills of the workforce due to the possibility of training. Both, the mobility of workers between sectors as well as the mobility of workers between skill-classes during trade liberalization, is highlighted in Result 2:

\section{Result 2 [Worker Mobility]:}

a) As a country specializes in one industry, workers migrate from the sector with the comparative disadvantage to the sector with the comparative advantage.

b) As trade costs decrease, the share of skilled workers increases in both countries.

Figures 4 and 5 show the number of workers per sector and the share of skilled workers. As the activity in the economy shifts from the comparative disadvantage industry to the comparative advantage industry this has two distinct effects on the decisions of workers. On the one hand, unskilled workers move from the comparative disadvantage industry to the comparative advantage industry.

\footnotetext{
${ }^{19}$ The reader might have noticed that specialization and inter-industry trade do not increase for the whole range of trade costs. Rather, both reach a peak when trade costs are small. The reason for the decrease of inter-industry trade and specialization lies in the increased importance of intra-industry trade for low trade costs. We will explain this in more detail further below.
} 


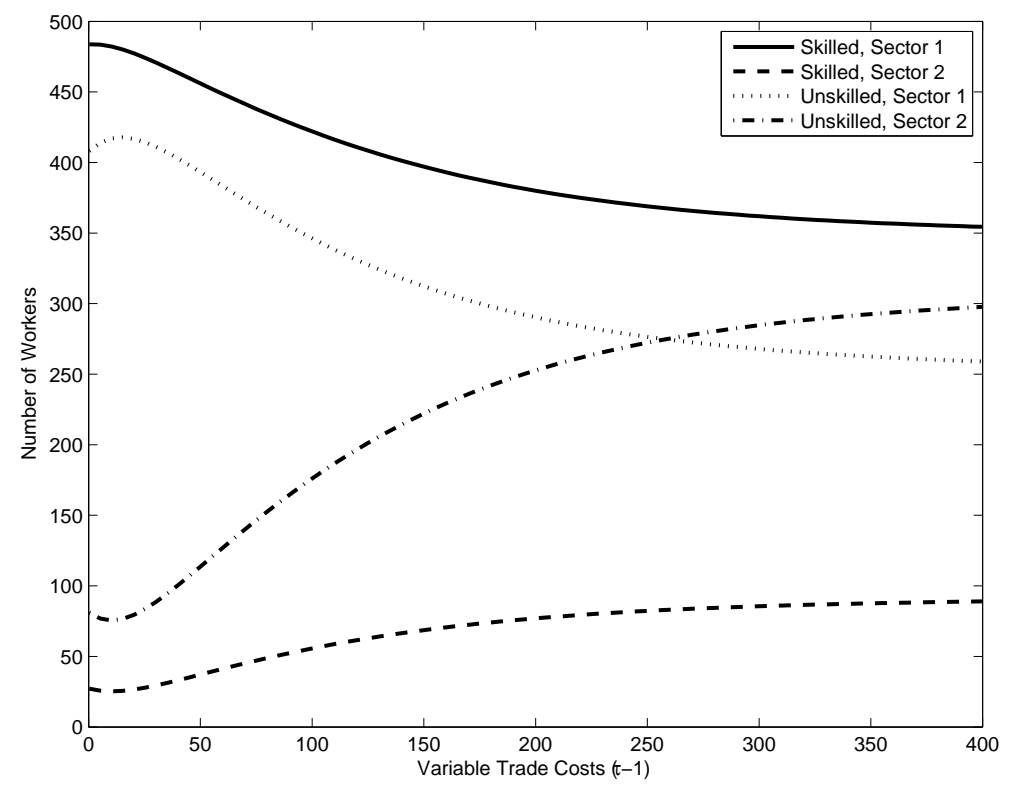

Figure 4: Workers per Sector

On the other hand, workers in the comparative disadvantage industry find it less profitable to invest in their human capital. Hence, the number of skilled workers in the comparative disadvantage sector decreases whereas it increases in the comparative advantage sector. It turns out that the increase of skilled workers in the comparative advantage industry outweighs the decrease in the comparative disadvantage industry leading to an increase in the total share of skilled workers.

Note that, even in the unskilled labor abundant foreign country the share of skilled workers increases when trade costs fall. The reason behind this increase is the same as for the home country. The increased demand in the unskilled labor intensive sector makes training in this sector more profitable. Hence, the number of skilled workers in this sector increases. This increase dominates the decrease of skilled workers in sector one, leading to an overall increase in the number of skilled workers.

So far we have described the overall change in the trade patterns and the resulting sectoral and compositional shifts of labor. Let us now investigate more closely the distributional consequences of trade liberalization. As the present model features two skill-groups and two different sectors, the trade liberalization effects can be studied separately for every skill-group in every industry. Result 3 summarizes the main findings: 


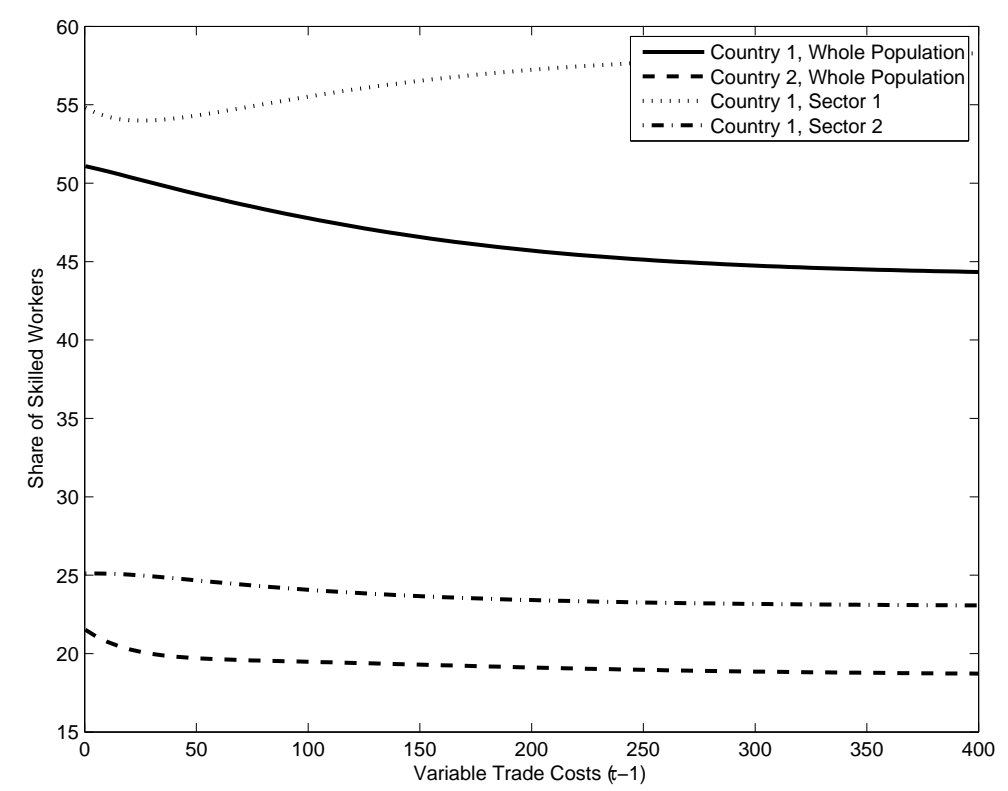

Figure 5: Share of Skilled Workers

\section{Result 3 [Disaggregate Labor Market Effects]:}

a) For skilled labor (the less mobile factor) the gains from trade are distributed very unequally, with workers in the comparative disadvantage industry loosing and workers in the comparative advantage industry gaining.

b) For unskilled labor (the more mobile factor) the effects are distributed more equally. In general, unskilled workers are worse off than skilled workers in the comparative advantage industry but better off than skilled workers in the comparative disadvantage industry.

The changes in unemployment and wages are mainly determined by three separate effects, only one of them present in the model of FPS with one sector. First, trade liberalization increases competition, driving out unproductive firms and thereby increasing average productivity. As already noted by FPS, trade liberalization will increase wages and decrease unemployment through this channel. Second, the patterns of specialization described above will imply changes in relative prices. The price in the export sector goes up and price in the import sector goes down. This will tend to decrease wages and increase unemployment in the import sector and increase wages and decrease unemployment in the export sector. On the other hand, we allow for mobility of workers, which is especially important for unskilled workers. Via this channel, differences in wages will cause migration of workers to counteract the effects on unemployment and to change 
the ratio of skilled to unskilled workers used in production. In this way, a rich and diverse picture of unemployment and wage effects evolves, and it depends very much on the level of trade costs and the skills of the worker, which effect is dominating.

Let us first look at the effects for skilled labor. As skilled labor is assumed to be less mobile, the third channel is less important. Again, we concentrate on the effects of trade liberalization, starting out with high levels of transport costs and postponing the discussion of low transport costs to further below. Figure 6 demonstrates how trade liberalization affects average productivity in the two sectors. The increased competition in the export sector drives up average productivity, while average productivity in the import sector increases only very little, unless trade costs become small. As discussed above, the increase in average productivity and the increase in the relative price work in the same direction so that in the export sector wages of skilled workers increase and unemployment falls. For skilled workers in the import sector there are two counteracting effects. Average productivity increases, but this effect is too small to dominate the effect of the decrease in the relative price. Hence, unemployment of skilled workers in the import-competing sector increases and wages decrease. This is shown in Figures 7 and 8 .

Let us now focus on the effects for unskilled workers. As for skilled labor, there is a competition effect and a specialization effect. These two effects would imply that unskilled workers in the export sector should earn higher wages. However, looking at Figure 8, we see that this is not the case. The reason lies in the third channel described above, namely the mobility of unskilled (unemployed) workers. The expansion of the skill intensive sector is accompanied by a movement of workers into this sector. However, only a few of these workers are good enough to afford the investment in training. This implies that the share of skilled to unskilled workers in sector one is going down. Given our Cobb-Douglas production function, it follows that, ceteris paribus, the marginal product of an unskilled worker goes down and therefore the wage decreases. Note, however, that the wage in the import sector decreases even more (due to the drop in the relative price of this sector), so that there is still an incentive for unskilled workers to move to sector one. The decrease in the marginal product of unskilled workers also explains why unemployment among unskilled workers in the export sector is going up, as shown in Figure 7. But why is unemployment of unskilled workers in the import sector going down? Again, the explanation is the possibility of unskilled workers to switch sectors. Unskilled workers are leaving the import-competing sector, leading to an increase of the prospects of the remaining workers in the import sector to find a job.

Summarizing these results we can say that for skilled labor, the relatively immobile factor, our model predicts similar outcomes as the Ricardo-Viner model does for the specific factors. The factor tied to the export industry gains, while the factor tied to the import industry looses. However, in the present model 


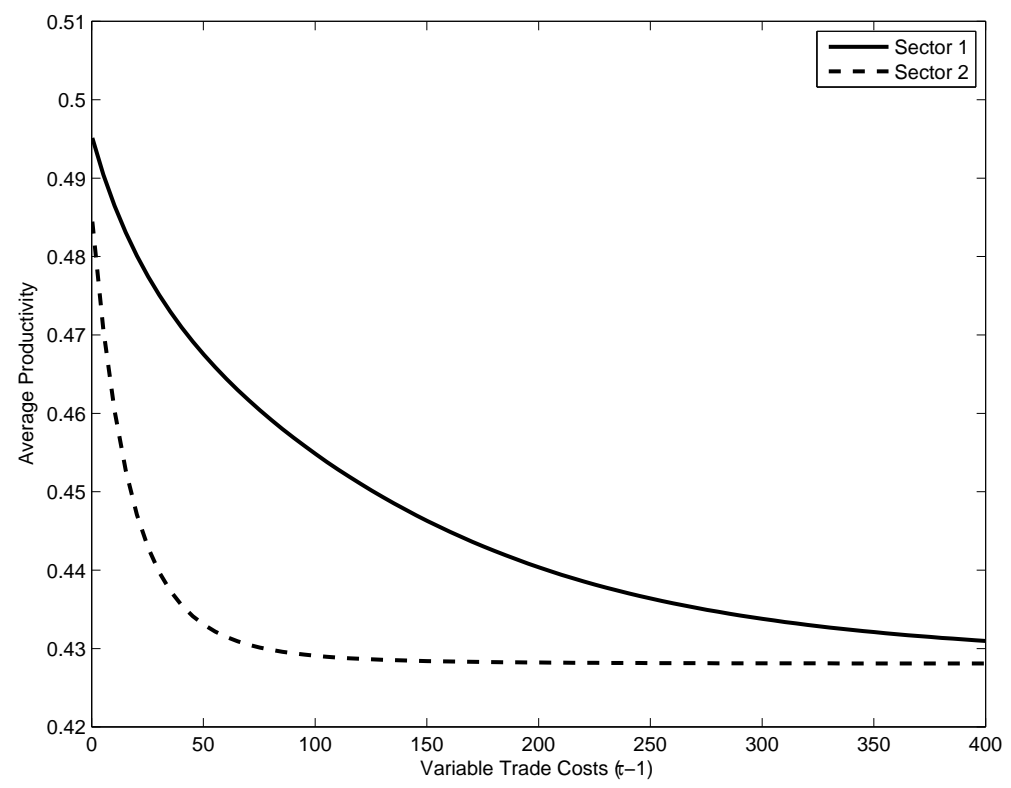

Figure 6: Average Productivity of Domestic Firms

the gains and losses are not only in terms of real wages, but also in terms of employment levels.

From Figures 7 and 8 it becomes also clear that the effects for unskilled labor are distributed more equally between industries. Again, this is due to the higher mobility of unskilled workers.

In all of the figures we have seen so far, there is a markable change in effects once trade costs have become small: The specialization of production is overturned, the unemployment rates for all factors and all sectors are dropping and all wages are increasing. All this is explained by the rising importance of intra-industry trade in sector two. Result 4 summarizes the role of intra-industry trade:

\section{Result 4 [Intra-industry trade]:}

For low trade costs, intra-industry trade improves productivity in the comparative disadvantage industry and thereby counteracts the effects of inter-industry trade.

As long as trade costs are relatively high, trade is about exploiting comparative advantages - the skill-abundant country exports the skill-intensive good, whereas the country abundantly endowed with unskilled labor exports the less skill-intensive good. However, once trade costs have become sufficiently low, love for variety becomes more and more important. Consumers generally value the slightly different varieties from the foreign country but for high trade costs these 


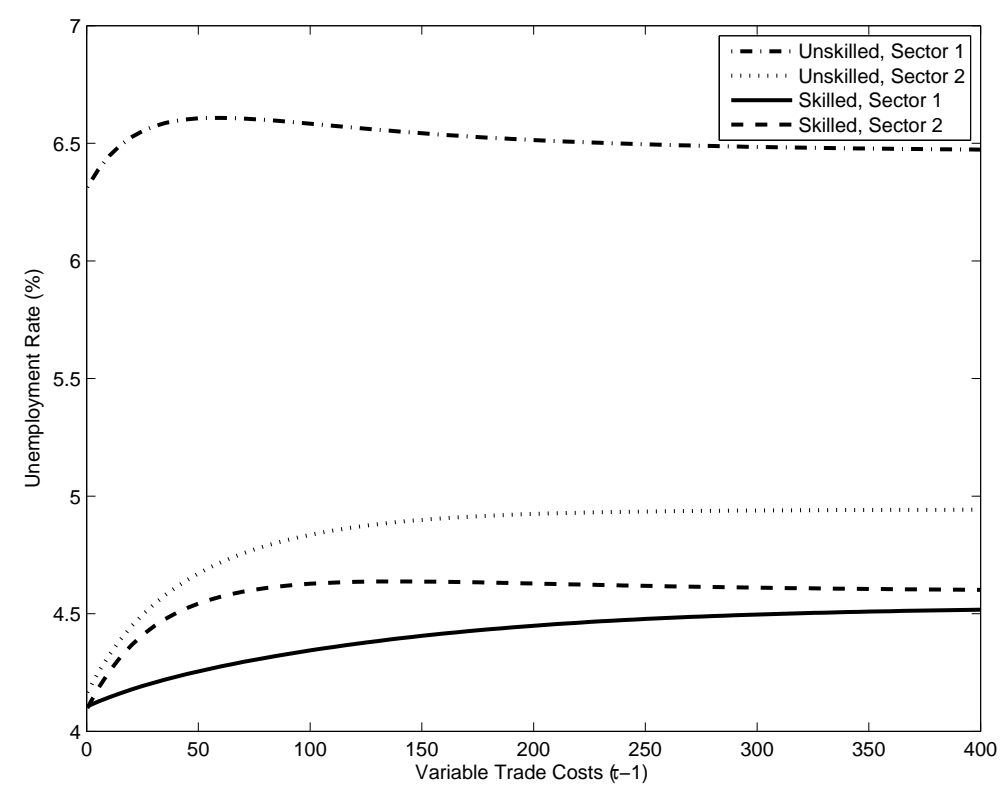

Figure 7: Unemployment

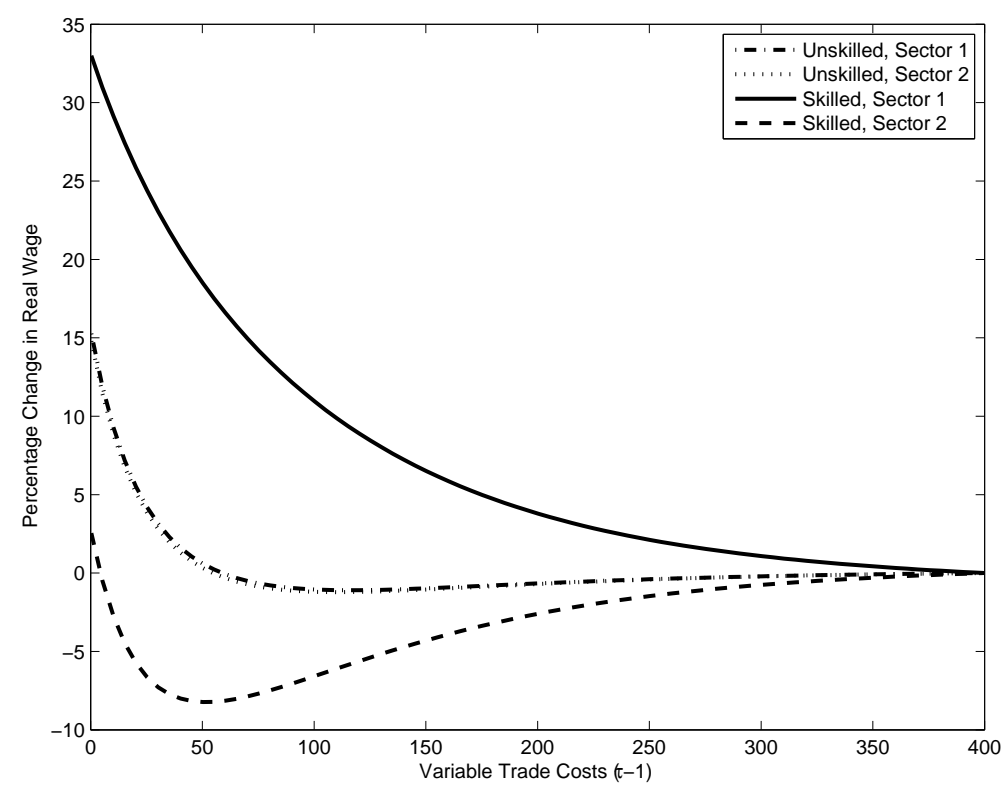

Figure 8: Real Wages 


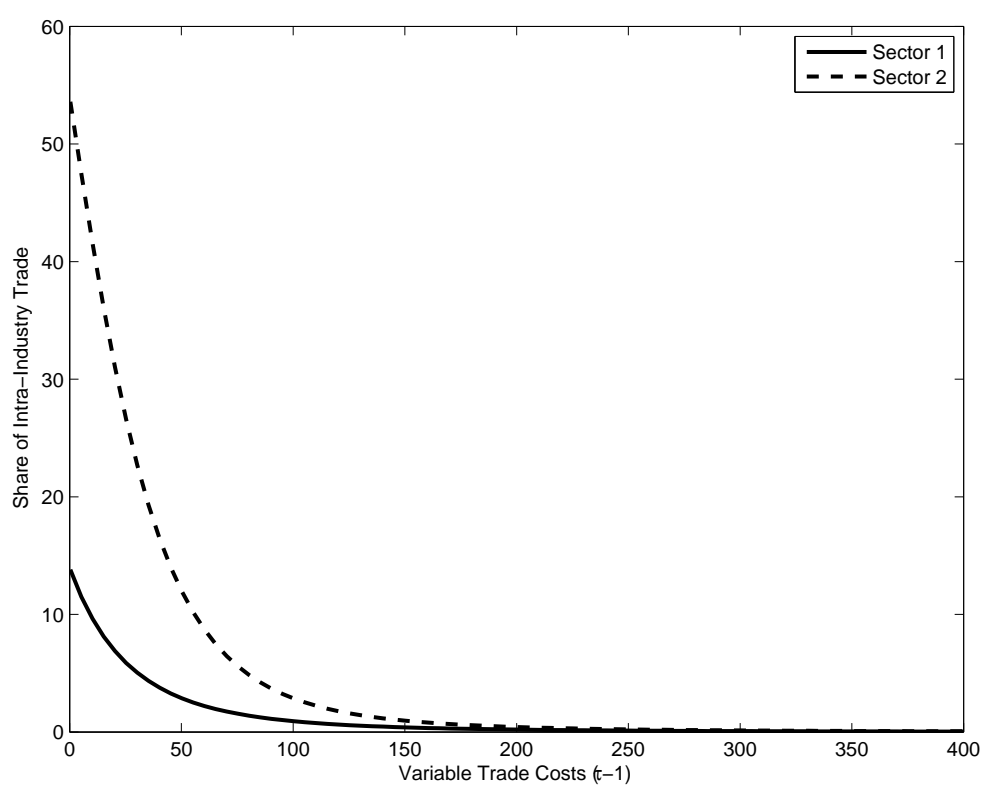

Figure 9: Intra-Industry Trade

differences are not worth exploiting. However, this changes once trade costs are sufficiently low, implying that the foreign country's demand for sector-two-goods from the home country rises. Although the foreign country can produce these goods relatively cheaper than the home country, the differing varieties imply that the foreign country will start exporting them, too.

This increase in exports in sector two has a big impact on competition in this sector. While the unproductive firms were well protected as long as trade was concentrated in sector one, they are now driven out of the market. This increases average productivity in the sector as can be seen from Figure 6, raises wages and thus makes the sector more attractive to workers. This effect weakens the aforementioned specialization trend and can even overturn it when trade costs become sufficiently low. In terms of the three separate employment effects, described further above, intra-industry trade increases productivity and thereby the importance of the productivity channel. For this reason employment and wages increase in both sectors and both skill-classes once trade costs are low.

The importance of intra-industry trade is best illustrated in Figure 9, showing the share of intra-industry trade in total production in the respective sector. While mainly negligible for relatively high trade costs, there is a sharp increase in intra-industry trade once trade costs drop below $100 \%$.

So far we have concentrated on the effects of trade liberalization in each of the two sectors separately. However, in the public debate the focus is very often on the whole population of unskilled versus skilled workers. Result 5 deals with this aspect: 


\section{Result 5 [Aggregate Labor Market Effects]:}

The relatively abundant factor gains more than the relatively scarce factor, both in terms of real wages and employment levels.

In Figure 10 we have aggregated the two sectors into averages of the whole population. For ease of interpretation, the graph is normalized by using the respective values under autarky. Hence, the graphs show the relative changes as compared to the situation under autarky.

The figures show that skilled labor, used intensively in the sector the home country specializes in, gains, whereas the effects for unskilled labor are ambiguous. Unskilled labor looses from trade liberalization if we start out with high values of trade costs. However, once trade barriers have fallen, even unskilled labor gains from further decreases in trade costs. ${ }^{20}$ The initial losses in income are very small and can therefore be compensated by the later gains. Hence under completely free trade the incomes of low-skilled workers will be higher than under autarky. However, the picture for unemployment looks a bit different. The increase in unemployment is substantial and reaches up to $10 \%$. The improvements for low trade costs are not sufficient to make up for the initial increases and so even for zero trade costs the unemployment rate is higher than under autarky.

One distinguishing feature of our model compared to other recent models dealing with trade liberalization effects on unemployment (see for example Egger and Kreickemeier (2008a,b), Helpman, Itskhoki and Redding (2008a,b), and Felbermayr, Prat and Schmerer (2008)) is the possibility to study the role of comparative advantages. To highlight the importance of comparative advantages, we run our simulations for different values of training costs, which is the source of comparative advantages in our model. Specifically, we set the training costs of the foreign country to the same value as for the home country in the baseline calibration, i.e. $\bar{k}_{i}^{H}=0.0105 \times P_{i}^{H}$ and $\bar{k}_{i}^{F}=0.0105 \times P_{i}^{F}$, leaving all other parameters unchanged. Then we increase the training costs of the foreign country step by step to the value of our baseline calibration $\left(\bar{k}_{i}^{F}=0.076 \times P_{i}^{F}\right)$. We then investigate how the effects of trade liberalization change when differences in the training costs increase. To summarize our results, we compare the average wage and the average unemployment under autarky with the situation in free trade. Hence, we calculate the percentage change that results from a switch from autarky to free trade for different values of training costs. The results for the home country are illustrated in Figure 11 and summarized in Result 6:

\footnotetext{
${ }^{20}$ It should be noted that the result that unskilled labor looses from trade liberalization for high values of trade costs is sensitive to the calibration of the model. However, the result that skilled labor in the home country gains more from trade liberalization is robust. For more details see the section on sensitivity analysis.
} 


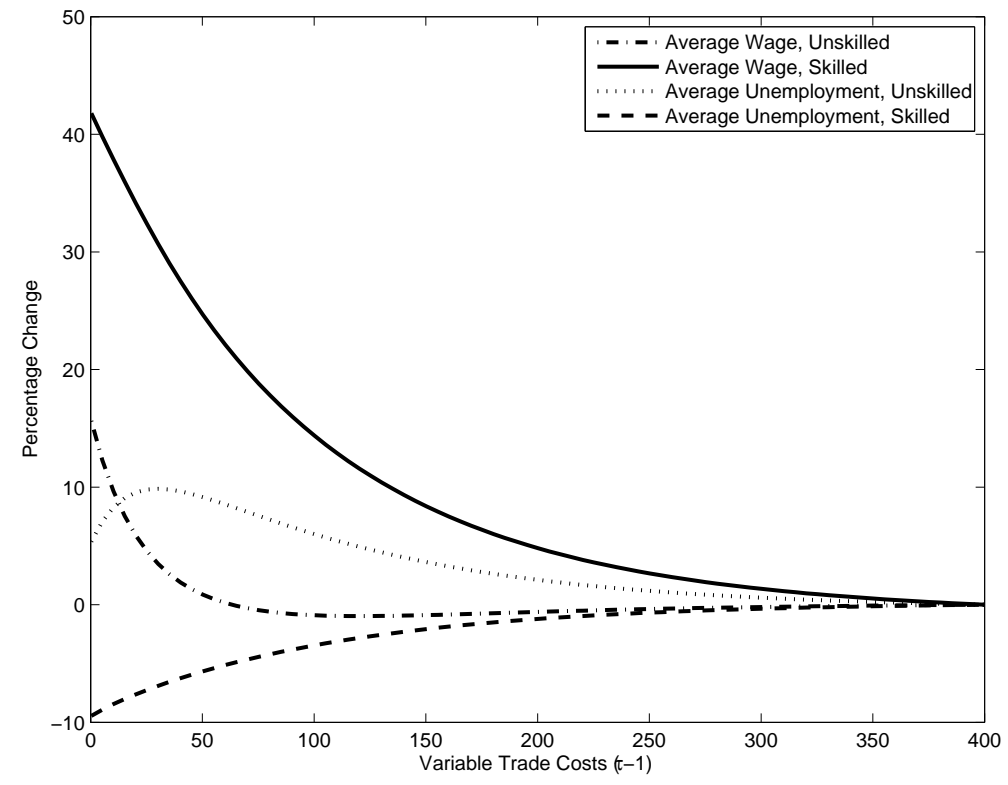

Figure 10: Average Unemployment and Average Wages

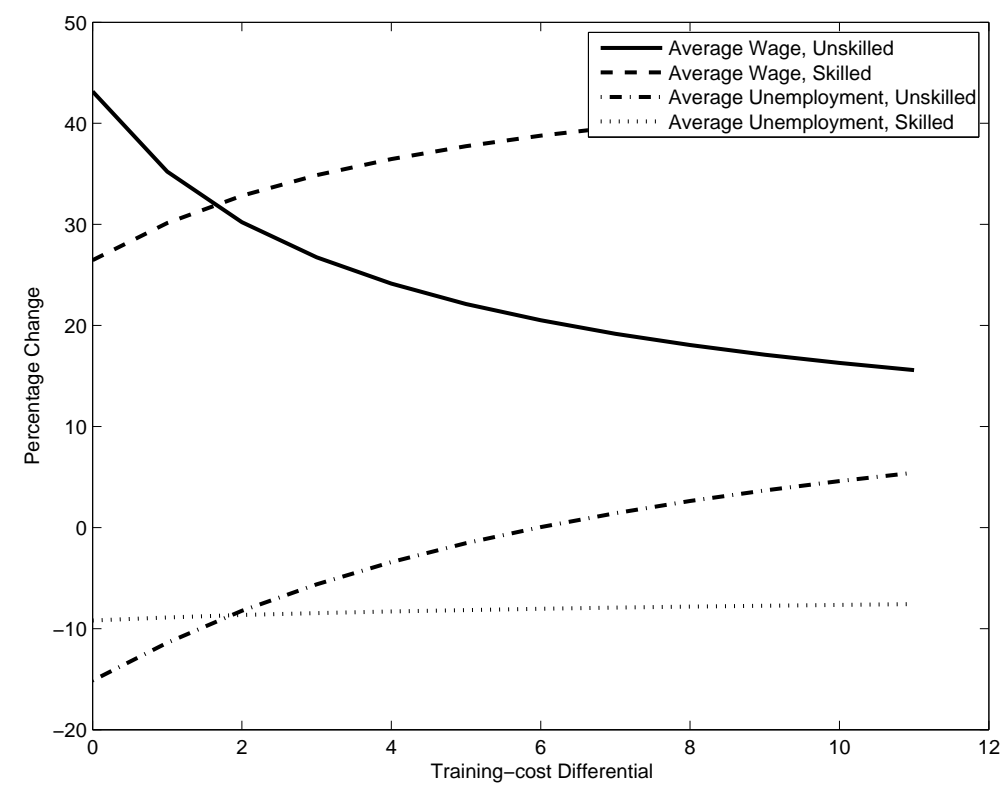

Figure 11: The Effects of Trade Liberalization and Comparative Advantage 


\section{Result 6 [Comparative Advantage]:}

The relatively abundant factor is better off if comparative advantages become stronger, whereas the relatively scarce factor is worse off. Stronger comparative advantages can even change the sign of the effects for unskilled labor concerning unemployment.

Starting from the left to the right, it gets relatively easier to train in order to become a skilled worker in the home country. Hence, the home country gets more and more skill abundant, leading to an increased comparative advantage in producing good one. The increasing comparative advantage is good news for skilled labor but not for unskilled labor. While unskilled labor is profiting much more from trade liberalization if there is no comparative advantage (see the left end of the figure), the picture changes completely if the comparative advantage becomes important (at the right end of the figure). Most remarkable are the effects for unemployment. Without comparative advantage, trade liberalization reduces the average unemployment rate of unskilled workers by $15 \%$. However, this effect becomes smaller for higher degrees of comparative advantage and in the end unemployment even increases. For skilled labor things are very different. While the unemployment rate is almost unaffected, the wage increases are much larger if the comparative advantage is strong.

The intuition for Result 6 lies in the differing importance of intra- and interindustry trade. As summarized in Result 4, intra-industry trade can have very different effects on average productivity and employment than inter-industry trade. If training-cost differences are low, countries are very similar, and trade is mainly intra-industry trade. Increased intra-industry trade leads to an increase of average productivity and a fall of unemployment in both sectors. If training-cost differences are large, inter-industry trade based on the comparative advantages of countries dominates. In this case unemployment rises for the relatively scarce factor.

These results may give a theoretical foundation for the large protests of many people against further trade liberalization. This protest against trade integration should be larger when it comes to the integration of less developed countries, and should stem mainly from people with lower levels of education. This is for example documented in the joint full report of Eurobarometer 61 and CC Eurobarometer 2004.1. ${ }^{21}$ It states at page B.3: "Overall, in the Union, young people and the most educated are more inclined to view globalisation as a positive phenomenon for their country." In the Flash EB 132/222 on page 31 the answers to the question "Are you, personally, in favour, of the European Union enlargement?" it says: "It appears that the longer one spent studying, the more one is in favour of the enlargement."

\footnotetext{
${ }^{21}$ Publicly available at http://ec.europa.eu/public_opinion/cceb_en.htm.

${ }^{22}$ Publicly available at http://ec.europa.eu/public_opinion/flash/fl132_2_en.pdf.
} 


\section{Comparison to Bernard, Redding and Schott}

As we have seen in the last section, comparative advantages are at the heart if one wants to understand the fears and the distributional consequences of globalization. However, recent works investigating the distributional consequences and allowing for unemployment do not allow for comparative advantages due to factor endowment differences (see for example Egger and Kreickemeier (2008a,b), Helpman, Itskhoki and Redding (2008a,b), and Felbermayr, Prat and Schmerer (2008)). BRS is one notable exception that allows for factor endowment driven comparative advantages in a model with heterogeneous firms. Hence, we want to compare our results with the predictions of the model of BRS.

In comparing the results, we first have to note that BRS assume a Walrasian labor market. Hence, there is no scope to study the effects of trade liberalization for unemployment. Remembering the quote at the beginning, unemployment seems to be at the focus of public interest when it comes to the evaluation of trade liberalization. Our model is capable of analyzing unemployment rates, and the results are shown in Figure 7. Further, we can investigate the impact of trade liberalization on the welfare of unemployed workers.

Both models, the model of BRS and our suggested model, predict real wage changes for unskilled and skilled labor in the pace of trade liberalization. Due to our assumption of separate labor markets, training possibilities of unskilled workers, and unemployment, our model does not lead to equalization of real wages across sectors. However, in the model of BRS, following the HeckscherOhlin assumption of perfect labor mobility between sectors, real unskilled and skilled labor wages between sectors are equalized. Figure 12 shows the changes of real wages of trade liberalization starting from autarky. Note, that we distinguish between unskilled and skilled workers and sectors. The main difference lies in the fate of skilled workers which (in our suggested model) depends heavily on the sector where they are employed. Real wages of skilled workers in the export sector rise, while real wages of skilled workers in the import sector fall. The reason is that the export sector expands, which is the skill-intensive sector in the home country. In the model of BRS the real wages of skilled workers increase heavily in both sectors. The reason is that the home country specializes in sector one, the skill-intensive sector, leading to a shift of workers form sector two to sector one. As workers are perfectly mobile, this reallocation takes place as long as wage differentials between sectors exist.

Actually, the shift of workers necessary to equalize wages between sectors in the model of BRS has consequences for several predictions. Most notably is the large increase in both, inter- and intra-industry trade. Whereas inter-industry trade is predicted to be 2.5-times larger in free trade in the model of BRS as compared to our suggested model, intra-industry trade in sector one (two) is even predicted 3-times (3.5-times) larger than in our results.

Empirically it is well known that the Heckscher-Ohlin model performs poorly 


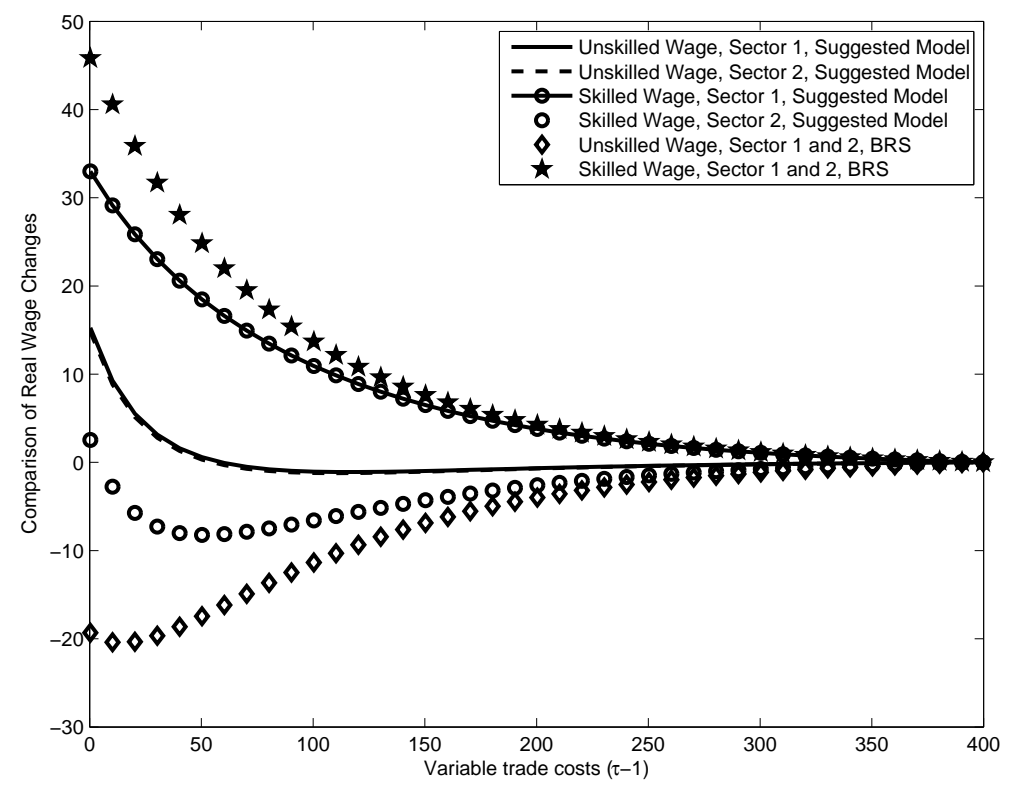

Figure 12: Comparison of Real Wages

(see for an overview Feenstra, 2004, chapter 2). One of the shortcomings is that implied factor services trade is much smaller than the factor-endowments predictions. This phenomenon is called "the case of the missing trade" (Trefler, 1995). As trade volume predictions in our model are much smaller than the ones from the BRS model based on the Heckscher-Ohlin framework, considering separated labor markets and introducing unemployment may provide empirical guidelines along which the puzzle of the "missing trade" may be solved. ${ }^{23}$

\section{Sensitivity Analysis}

In this section we want to the analyze the qualitative and quantitative impact of various parameters on the results illustrated above. For brevity, we do not include figures in this section. However, all figures underlying the analysis are available as a supplement to the paper. As in the BRS- and the Heckscher-Ohlin-model and as already discussed above, our main results are driven by comparative advantages between countries. In our case these comparative advantages stem from differing training technologies. A country which offers its worker better training possibilities will have more skilled workers and thus a comparative advantage in the production of skill-intensive goods. It was demonstrated that in such a

\footnotetext{
${ }^{23}$ These are by no means the only possibilities to solve the "missing trade" puzzle. Technological differences are the prime candidate to make the Heckscher-Ohlin predictions fit the data and where investigated heavily in the literature (see Feenstra, 2004).
} 
setup trade liberalization will benefit skilled workers, reducing their unemployment rates and increasing their wages.

It was also shown that decreasing the role of comparative advantage by lowering the differences in training costs has important implications for the outcome of the model. Thus it is not very surprising that other parameters, affecting the importance of comparative advantage have similar consequences. These parameters are the share of skilled workers in production, $\beta$, and the importance of the skill-intensive good in the utility-function, $\alpha$.

In our baseline calibration we assumed that sector one is skill-intensive with $\beta_{1}=0.8$ and that the other sector produces with $\beta_{2}=0.2$. Reducing the difference in the $\beta$ 's by lowering $\beta_{1}$ and simultaneously increasing $\beta_{2}$ decreases the importance of comparative advantages because the production technologies of both sectors become more similar. For skilled labor this has no qualitative effect. Quantitatively the impact of trade liberalization is somewhat smaller, but skilled labor is still gaining unambiguously. On the contrary, the losses of unskilled labor become smaller with the decreasing difference in the $\beta$ 's and can even be overturned into gains. For the constellation $\beta_{1}=0.6$ and $\beta_{2}=0.4$ unskilled labor is, as skilled labor, unambiguously gaining from trade liberalization, although the gains are still smaller than the gains for skilled labor.

Very similar are the effects for a decrease of the importance of the skillintensive good in the utility function $\alpha$. Again the results for skilled labor are only quantitatively affected, but not qualitatively, while for unskilled labor the losses in wages can be overturned to wage-increases. However, trade liberalization initially still increases unemployment of unskilled workers. This increase is lowered by decreasing the value of $\alpha$. But even for $\alpha=0.5$ unemployment rises with beginning trade liberalization and only falls for low trade costs and the onset of intra-industry trade (as in our baseline calibration).

Other key parameters of the model, like the elasticity of substitution $\sigma$, the bargaining power of workers $\mu$ and the replacement rate of unemployment benefits $b$, only have quantitative impacts on the level of unemployment. However, the result that trade liberalization initially harms unskilled workers still holds.

\section{Conclusions}

The question how gains from trade are distributed has a long history in international trade. As long as the history is, as diverse are the answers. Two of the most prominent international trade models, the Heckscher-Ohlin model and the Ricardo-Viner model, for example, lead to very different predictions regarding the distributions of trade gains. One of the keys to understand these differences is to consider the different possibilities to react to changes in the economic environment. Whereas factors are perfectly mobile between sectors in the Heckscher-Ohlin model, the Ricardo-Viner model assumes factors that are 
specific to sectors.

As the possibilities to switch sectors as well as to train oneself seem to be important mechanisms to respond to trade liberalization, one of our main contributions is to incorporate an endogenous selection of people to sectors and skillclasses. Specifically, we propose a model with two factors, two sectors, search and matching unemployment and endogenous worker flows. Further we allow for heterogeneous firms with varying productivities, which copes with the most recent empirical findings of varying firm sizes and export status.

We show that trade liberalization can have very diverse effects for the different skill-classes. As trade costs decrease, a country with a relative advantage in the training technology will specialize in the production of the skill-intensive good. Workers will migrate to this sector and invest more in their human capital.

The big winners are the skilled workers in the export sector, while skilled workers in the import sector loose. In this respect our model replicates the result of the famous Ricardo-Viner model, which argues that the fate of an immobile factor will be linked to the fate of the sector where it is employed. Thus, a factor linked to the export sector will gain, while a factor linked to the import sector will loose.

On the other hand, the effects for unskilled labor (the more mobile factor) are much more equally distributed. In line with the Heckscher-Ohlin model, in the country exporting the skill-intensive good, unskilled labor will suffer losses, leading to an increase of unemployment and a decrease of wages. Only for low trade costs, intra-industry trade can overturn this result.

These results may help to explain why specifically people with low education levels in developed countries fear opening the borders to less developed countries, whereas higher educated people are generally more in favor of globalization. Furthermore, our trade volume predictions are much lower than the ones from comparable models without separated labor markets and unemployment. Hence, considering disintegrated labor markets and unemployment may be fruitful to shed further light on the "case of the missing trade".

One interesting policy conclusion is the importance of training possibilities for unskilled, unemployed labor. In order to react to increased globalization, countries may want to encourage people to investigate in their human capital. Studying different policy instruments to encourage and finance training would therefore be a fruitful road for further research. 


\section{Appendix}

\section{A1 Derivation of Equation (7) and Equaliza- tion of Marginal Revenues}

To show that $p_{x}\left[\varphi_{i}^{H}\right]=\tau p_{d}\left[\varphi_{i}^{H}\right]$, we proceed as follows. First, according to Equation (4):

$$
\begin{aligned}
& p_{d}\left[\varphi_{i}^{H}\right]=q_{d}\left[\varphi_{i}^{H}\right]^{-\frac{1}{\sigma}}\left(P_{i}^{H}\right)^{\frac{\sigma-1}{\sigma}}\left(\frac{\alpha_{i} Y^{H}}{M^{H}}\right)^{\frac{1}{\sigma}}, \\
& p_{x}\left[\varphi_{i}^{H}\right]=q_{x}\left[\varphi_{i}^{H}\right]^{-\frac{1}{\sigma}}\left(P_{i}^{F}\right)^{\frac{\sigma-1}{\sigma}}\left(\frac{\tau \alpha_{i} Y^{F}}{M^{F}}\right)^{\frac{1}{\sigma}} .
\end{aligned}
$$

Hence, revenues on the domestic and foreign market are given by:

$$
\begin{aligned}
& R_{d}\left[\varphi_{i}^{H}\right]=q_{d}\left[\varphi_{i}^{H}\right]^{\frac{\sigma-1}{\sigma}}\left(P_{i}^{H}\right)^{\frac{\sigma-1}{\sigma}}\left(\frac{\alpha_{i} Y^{H}}{M^{H}}\right)^{\frac{1}{\sigma}}, \\
& R_{x}\left[\varphi_{i}^{H}\right]=q_{x}\left[\varphi_{i}^{H}\right]^{\frac{\sigma-1}{\sigma}}\left(P_{i}^{F}\right)^{\frac{\sigma-1}{\sigma}}\left(\frac{\tau^{1-\sigma} \alpha_{i} Y^{F}}{M^{F}}\right)^{\frac{1}{\sigma}} .
\end{aligned}
$$

Now taking partial derivatives with respect to $L_{i}^{H}$ and using Equation (6) leads to:

$$
\begin{aligned}
& \frac{\partial R_{d}\left[\varphi_{i}^{H}\right]}{\partial L_{i d}^{H}}=\frac{\sigma-1}{\sigma} q_{d}\left[\varphi_{i}^{H}\right]^{-\frac{1}{\sigma}}\left(P_{i}^{H}\right)^{\frac{\sigma-1}{\sigma}}\left(\frac{\alpha_{i} Y^{H}}{M^{H}}\right)^{\frac{1}{\sigma}} \varphi_{i}^{H}\left(1-\beta_{i}\right)\left(\frac{S_{d}\left[\varphi_{i}^{H}\right]}{L_{d}\left[\varphi_{i}^{H}\right]}\right)^{\beta_{i}}, \\
& \frac{\partial R_{x}\left[\varphi_{i}^{H}\right]}{L_{i x}^{H}}=\frac{\sigma-1}{\sigma} q_{x}\left[\varphi_{i}^{H}\right]^{-\frac{1}{\sigma}}\left(P_{i}^{F}\right)^{\frac{\sigma-1}{\sigma}}\left(\frac{\tau^{1-\sigma} \alpha_{i} Y^{F}}{M^{F}}\right)^{\frac{1}{\sigma}} \varphi_{i}^{H}\left(1-\beta_{i}\right)\left(\frac{S_{x}\left[\varphi_{i}^{H}\right]}{L_{x}\left[\varphi_{i}^{H}\right]}\right)^{\beta_{i}},
\end{aligned}
$$

where $L_{d}\left[\varphi_{i}^{H}\right]\left(L_{x}\left[\varphi_{i}^{H}\right]\right)$ denotes unskilled labor inputs for domestic (foreign) production of a firm in industry $i$ in country $H$ with productivity $\varphi_{i}^{H}$. Similarly, $S_{d}\left[\varphi_{i}^{H}\right]\left(S_{x}\left[\varphi_{i}^{H}\right]\right)$ denotes skilled labor inputs for domestic (foreign) production of a firm in industry $i$ in country $H$ with productivity $\varphi_{i}^{H}$.

Noting that we assume a Cobb-Douglas production function which is linear homogeneous, the ratios $S_{d}\left[\varphi_{i}^{H}\right] / L_{d}\left[\varphi_{i}^{H}\right]$ and $S_{x}\left[\varphi_{i}^{H}\right] / L_{x}\left[\varphi_{i}^{H}\right]$ are equal. Hence, we can reformulate as follows:

$$
\begin{aligned}
& \frac{\partial R_{d}\left[\varphi_{i}^{H}\right]}{\partial L_{i d}^{H}}=\frac{\sigma-1}{\sigma} p_{d}\left[\varphi_{i}^{H}\right]\left(1-\beta_{i}\right)\left(\frac{S_{d}\left[\varphi_{i}^{H}\right]}{L_{d}\left[\varphi_{i}^{H}\right]}\right)^{\beta_{i}}, \\
& \frac{\partial R_{x}\left[\varphi_{i}^{H}\right]}{\partial L_{i x}^{H}}=\frac{\sigma-1}{\sigma} \tau^{-1} p_{x}\left[\varphi_{i}^{H}\right]\left(1-\beta_{i}\right)\left(\frac{S_{d}\left[\varphi_{i}^{H}\right]}{L_{d}\left[\varphi_{i}^{H}\right]}\right)^{\beta_{i}} .
\end{aligned}
$$

This shows that when firms want to equalize marginal revenues across markets, $p_{x}\left[\varphi_{i}^{H}\right]=\tau p_{d}\left[\varphi_{i}^{H}\right]$ immediately follows. 


\section{A2 Derivation of Equation (11)}

The envelope condition of the dynamic programming problem is found by differentiating the value function (Equation (9)) with respect to the state variables $L_{i}\left(S_{i}\right)$. Isolating the shadow value of employment yields:

$$
\begin{aligned}
\lambda_{L i, t}^{H} & =\frac{1}{1+r}\left[\frac{\partial R\left[\varphi_{i}^{H}\right]}{\partial L_{i}^{H}}-w_{L i}^{H}-\frac{\partial w_{L i}^{H}}{\partial L_{i}^{H}} L_{i}^{H}+(1-\rho)(1-\delta) \lambda_{L i, t+1}^{H}\right], \\
\lambda_{S i, t}^{H} & =\frac{1}{1+r}\left[\frac{\partial R\left[\varphi_{i}^{H}\right]}{\partial S_{i}^{H}}-w_{S i}^{H}-\frac{\partial w_{S i}^{H}}{\partial S_{i}^{H}} S_{i}^{H}+(1-\rho)(1-\delta) \lambda_{S i, t+1}^{H}\right] .
\end{aligned}
$$

In steady state, $\lambda_{L i, t}^{H}=\lambda_{L i, t+1}^{H}$ and $\lambda_{S i, t}^{H}=\lambda_{S i, t+1}^{H}$. Hence, the above equations simplify to:

$$
\begin{aligned}
\lambda_{L i}^{H} & =\frac{\frac{\partial R\left[\varphi_{i}^{H}\right]}{\partial L_{i}^{H}}-w_{L i}^{H}-\frac{\partial w_{L i}^{H}}{\partial L_{i}^{H}} L_{i}^{H}}{r+s}, \\
\lambda_{S i}^{H} & =\frac{\frac{\partial R\left[\varphi_{i}^{H}\right]}{\partial S_{i}^{H}}-w_{S i}^{H}-\frac{\partial w_{S i}^{H}}{\partial S_{i}^{H}} S_{i}^{H}}{r+s},
\end{aligned}
$$

where $s=\delta+\rho-\rho \delta$.

Combining Equations (10) and (A7) yields Equation (11).

\section{A3 Derivation of Equations (13) and (14)}

To solve the surplus-splitting rule given by Equation (12), notice that the optimality condition (10) does not vary with the level of the control variables $v_{L i}^{H}, v_{S i}^{H}$. Hence, the optimal firm size remains constant through time, so that $L_{i}^{H}=\left(L_{i}^{H}\right)^{\prime}$ and $S_{i}^{H}=\left(S_{i}^{H}\right)^{\prime}$. This steady-state condition and the envelope theorem enable us to write the FOC as given in Equation (A7).

Reinserting these expressions together with the workers' gains from employment, $E_{L i}^{H}\left[\varphi_{i}^{H}\right]-U_{L i}^{H}=\left(w_{L i}^{H}-(r+d) U_{L i}^{H}\right) /(r+s)$ and $E_{S i}^{H}\left[\varphi_{i}^{H}\right]-U_{S i}^{H}=\left(w_{S i}^{H}-\right.$ $\left.(r+d) U_{S i}^{H}\right) /(r+s)$, into the "surplus-splitting" Equation (12) yields:

$$
\begin{aligned}
& w_{L i}^{H}=\mu \frac{\partial R\left[\varphi_{i}^{H}\right]}{\partial L_{i}^{H}}-\mu \frac{\partial w_{L i}^{H}}{\partial L_{i}^{H}} L_{i}^{H}+(1-\mu)(r+d) U_{L i}^{H}, \\
& w_{S i}^{H}=\mu \frac{\partial R\left[\varphi_{i}^{H}\right]}{\partial S_{i}^{H}}-\mu \frac{\partial w_{S i}^{H}}{\partial S_{i}^{H}} S_{i}^{H}+(1-\mu)(r+d) U_{S i}^{H} .
\end{aligned}
$$

These two equations are linear differential equations in $L_{i}^{H}$ and $S_{i}^{H}$, respectively. The solution is given by:

$$
\begin{aligned}
& w_{L i}^{H}=(1-\mu)(r+d) U_{L i}^{H}+\mu\left(\frac{\sigma}{\sigma+\beta_{i} \mu-\mu-\beta_{i} \sigma \mu}\right) \frac{\partial R\left[\varphi_{i}^{H}\right]}{\partial L_{i}^{H}}, \\
& w_{S i}^{H}=(1-\mu)(r+d) U_{S i}^{H}+\mu\left(\frac{\sigma}{\left.\sigma-\beta_{i} \mu+\beta_{i} \sigma \mu-\sigma \mu\right)}\right) \frac{\partial R\left[\varphi_{i}^{H}\right]}{\partial S_{i}^{H}} .
\end{aligned}
$$


This can be seen by noting that

$$
\frac{\partial R\left[\varphi_{i}^{H}\right]}{\partial L_{i}^{H}}=\frac{\partial R_{d}\left[\varphi_{i}^{H}\right]}{\partial L_{i}^{H}}=\frac{\partial R_{x}\left[\varphi_{i}^{H}\right]}{\partial L_{i}^{H}}=\frac{\sigma-1}{\sigma} p_{d}\left[\varphi_{i}^{H}\right]\left(1-\beta_{i}\right)\left(\frac{S\left[\varphi_{i}^{H}\right]}{L\left[\varphi_{i}^{H}\right]}\right)^{\beta_{i}},
$$

as firms equate marginal revenues across markets and either employ the marginal worker for domestic or foreign production.

The job-creation curve is derived by reinserting the revenue function into Equations (A9) and differentiating the resulting equations with respect to $L_{i}^{H}$ and $S_{i}^{H}$, respectively:

$$
\begin{aligned}
\frac{\partial w_{L i}^{H}}{\partial L_{i}^{H}} & =\frac{\mu}{L_{i}^{H}}\left(\frac{\beta_{i}-1-\beta_{i} \sigma}{\sigma+\beta_{i} \mu-\mu-\beta_{i} \sigma \mu}\right) \frac{\partial R\left[\varphi_{i}^{H}\right]}{\partial L_{i}^{H}} \\
\frac{\partial w_{S i}^{H}}{\partial S_{i}^{H}} & =\frac{\mu}{S_{i}^{H}}\left(\frac{-\beta_{i}+\beta_{i} \sigma-\sigma}{\sigma-\beta_{i} \mu+\beta_{i} \sigma \mu-\sigma \mu}\right) \frac{\partial R\left[\varphi_{i}^{H}\right]}{\partial S_{i}} .
\end{aligned}
$$

We can now substitute $\left(\partial w_{L i}^{H} / \partial L_{i}^{H}\right) L_{i}^{H}$ and $\left(\partial w_{S i}^{H} / \partial S_{i}^{H}\right) S_{i}^{H}$ in Equation (11) to obtain:

$$
\begin{aligned}
\frac{\partial R\left[\varphi_{i}^{H}\right]}{\partial L_{i}^{H}} & =\frac{c P_{i}^{H}}{m\left[\theta_{L i}^{H}\right]} \frac{s+r}{1-\delta}+w_{L i}^{H}+\frac{\partial w_{L i}^{H}}{\partial L_{i}^{H}} L\left[\varphi_{i}^{H}\right] \Rightarrow \\
\frac{\partial R\left[\varphi_{i}^{H}\right]}{\partial L_{i}^{H}} & =\frac{c P_{i}^{H}}{m\left[\theta_{L i}^{H}\right]} \frac{s+r}{1-\delta}+w_{L i}^{H} \\
& +\left(\mu\left(\frac{\beta_{i}-1-\beta_{i} \sigma}{\sigma+\beta_{i} \mu-\mu-\beta_{i} \sigma \mu}\right) \frac{\partial R\left[\varphi_{i}^{H}\right]}{\partial L_{i}^{H}}\right) \Rightarrow \\
w_{L i}^{H} & =\left(\frac{\sigma}{\sigma+\beta_{i} \mu-\mu-\beta_{i} \sigma \mu}\right) \frac{\partial R\left[\varphi_{i}^{H}\right]}{\partial L_{i}^{H}} \\
& -\frac{c P_{i}^{H}}{m\left[\theta_{L i}^{H}\right]} \frac{s+r}{1-\delta} . \\
\frac{\partial R\left[\varphi_{i}^{H}\right]}{\partial S_{i}^{H}} & =\frac{c P_{i}^{H}}{m\left[\theta_{S i}^{H}\right]} \frac{s+r}{1-\delta}+w_{S i}^{H}+\frac{\partial w_{S i}^{H}}{\partial S_{i}^{H}} S_{i}^{H} \Rightarrow \\
\frac{\partial R\left[\varphi_{i}^{H}\right]}{\partial S_{i}^{H}} & =\frac{c P_{i}^{H}}{m\left[\theta_{S i}^{H}\right]} \frac{s+r}{1-\delta}+w_{S i}^{H} \\
& +\left(\mu\left(\frac{-\beta_{i}+\beta_{i} \sigma-\sigma}{\sigma-\beta_{i} \mu+\beta_{i} \sigma \mu-\sigma \mu}\right) \frac{\partial R\left[\varphi_{i}^{H}\right]}{\partial S_{i}^{H}}\right) \Rightarrow \\
w_{S i}^{H} & =\left(\frac{\sigma R\left[\varphi_{i}^{H}\right]}{\partial-\beta_{i} \mu+\beta_{i} \sigma \mu-\sigma \mu}\right) \frac{\partial S_{i}^{H}}{m\left[\theta_{S i}^{H}\right]} \frac{s+r}{1-\delta} . \\
& -\frac{c P_{H}^{H}}{m}
\end{aligned}
$$


Plugging in Equation (A10) into Equations (A12) and (A13) directly yields (13).

Finally, we express the Wage Curves as a function of $\theta_{L i}^{H}$ and $\theta_{S i}^{H}$, respectively, by reinserting (A9) into (A12) and (A13):

$$
\begin{aligned}
& w_{L i}^{H}=(1-\mu)(r+d) U_{L i}^{H}+\mu\left(w_{L i}^{H}+\frac{c P_{i}^{H}}{m\left[\theta_{L i}^{H}\right]} \frac{s+r}{1-\delta}\right), \\
& w_{S i}^{H}=(1-\mu)(r+d) U_{S i}^{H}+\mu\left(w_{S i}^{H}+\frac{c P_{i}^{H}}{m\left[\theta_{S i}^{H}\right]} \frac{s+r}{1-\delta}\right) .
\end{aligned}
$$

Isolating the wage on the left-hand side yields Equation (14).

To substitute out the value of unemployment, note that the value functions of skilled workers are (the same relationships hold for unskilled workers):

$$
\begin{aligned}
U_{S i}^{H} & =\frac{1}{1+r}\left(b+(1-d) \theta_{S i}^{H} m\left[\theta_{S i}^{H}\right] E_{S i}^{H}+(1-d)\left(1-\theta_{S i}^{H} m\left[\theta_{S i}^{H}\right]\right) U_{S i}^{H}\right), \\
E_{S i}^{H} & =\frac{1}{1+r}\left(w_{S i}^{H}+(1-s) E_{S i}^{H}+(s-d) U_{S i}^{H}\right) .
\end{aligned}
$$

where $\theta_{S i}^{H} m\left[\theta_{S i}^{H}\right]$ is an unemployed workers probability to find a new job and $b$ are unemployment benefits. The two equations can be combined to:

$$
(r+d) U_{S i}^{H}=b+(1-d) \theta_{S i}^{H} m\left[\theta_{S i}^{H}\right] \frac{w_{S i}^{H}-(r+d) U_{S i}^{H}}{r+s} .
$$

Using the wage curve (14) to substitute out $w_{S i}^{H}-(r+d) U_{S i}^{H}$ this becomes:

$$
(r+d) U_{S i}^{H}=b+\frac{c P_{i}^{H} \theta_{S i}^{H}}{1-\delta} \frac{\mu}{1-\mu} .
$$

Substituting this into Equation (14) yields (15).

\section{A4 Productivity Cut-Off Relationship}

As in BRS, equilibrium revenue in the export market is proportional to that in the domestic market. However, the relative revenue in the export market now depends on variable trade costs, and price indices now vary across the two countries. Hence, relative price indices enter as a determinant of relative revenue in the export market:

$$
R_{x}\left[\varphi_{i}^{H}\right]=\tau^{1-\sigma}\left(\frac{P_{i}^{F}}{P_{i}^{H}}\right)^{\sigma-1}\left(\frac{Y^{F} M^{H}}{Y^{H} M^{F}}\right) R_{d}\left[\varphi_{i}^{H}\right] .
$$

The zero-productivity cut-off above which firms produce for the domestic market, $\varphi_{i d}^{* H}$, and the costly trade exporting productivity cut-off, above which 
firms produce for both the domestic and the export markets, $\varphi_{i x}^{* H}$, are determined by:

$$
\begin{aligned}
& R_{d}\left[\varphi_{i d}^{* H}\right]=\sigma f P_{i}^{H} \\
& R_{x}\left[\varphi_{i x}^{* H}\right]=\sigma f_{x} P_{i}^{H}
\end{aligned}
$$

Combining these two equations leads to an equation that links the revenues of a firm at the zero-profit productivity cut-off to those of a firm at the exporting productivity cut-off. Further, the relationship between revenues of two firms with different productivities in the same industry and country is given by: $R_{d}\left[\varphi_{i d}^{\prime \prime H}\right]=\left(\frac{\varphi_{i d}^{\prime \prime H}}{\varphi_{i d}^{\prime H}}\right)^{\sigma-1} R_{d}\left[\varphi_{i d}^{\prime H}\right]$. These two relationships together yield and equilibrium relationship between the two productivity cut-offs:

$$
\begin{array}{r}
\varphi_{i x}^{* H}=\Lambda_{i}^{H} \varphi_{i d}^{* H}, \quad \text { where } \\
\Lambda_{i}^{H} \equiv \tau\left(\frac{P_{i}^{H}}{P_{i}^{F}}\right)\left(\frac{Y^{H} M^{F}}{Y^{F} M^{H}} \frac{f_{x}}{f}\right)^{\frac{1}{\sigma-1}} .
\end{array}
$$

\section{A5 Parameter Restriction for $\beta_{i} / \sigma / \mu$}

First we solve for the quantities produced by one firm by using the zero-profit condition of firms:

$$
\frac{(1-\delta)}{r+\delta} \pi_{d}\left[\varphi_{i d}^{* H}\right]=f P_{i}^{H}+\frac{c P_{i}^{H} L\left[\varphi_{i d}^{* H}\right]}{m\left[\theta_{L i}^{H}\right]}+\frac{c P_{i}^{H} S\left[\varphi_{i d}^{* H}\right]}{m\left[\theta_{S i}^{H}\right]} .
$$

Plugging in this expression into the profit function yields:

$$
\begin{aligned}
& \frac{(1-\delta)}{r+\delta}\left[q_{d}\left[\varphi_{i d}^{* H}\right] p_{d}\left[\varphi_{i d}^{* H}\right]-w_{L i}^{H} L\left[\varphi_{i d}^{* H}\right]-w_{S i}^{H} S\left[\varphi_{i d}^{* H}\right]-\frac{c P_{i}^{H} L\left[\varphi_{i d}^{* H}\right] \rho}{m\left[\theta_{L i}^{H}\right]}-\right. \\
& \left.\frac{c P_{i}^{H} S\left[\varphi_{i d}^{* H}\right] \rho}{m\left[\theta_{S i}^{H}\right]}-f P_{i}^{H}\right]=f P_{i}^{H}+\frac{c P_{i}^{H} L\left[\varphi_{i d}^{* H}\right]}{m\left[\theta_{L i}^{H}\right]}+\frac{c P_{i}^{H} S\left[\varphi_{i d}^{* H}\right]}{m\left[\theta_{S i}^{H}\right]} \Rightarrow \\
& \frac{(1-\delta)}{r+\delta}\left(q_{d}\left[\varphi_{i d}^{* H}\right] p_{d}\left[\varphi_{i d}^{* H}\right]-w_{L i}^{H} L\left[\varphi_{i d}^{* H}\right]-w_{S i}^{H} S\left[\varphi_{i d}^{* H}\right]\right) \\
& -\frac{r+s}{r+\delta}\left(\frac{c P_{i}^{H} L\left[\varphi_{i d}^{* H}\right]}{m\left[\theta_{L i}^{H}\right]}+\frac{c P_{i}^{H} S\left[\varphi_{i d}^{* H}\right]}{m\left[\theta_{S i}^{H}\right]}\right)=\frac{1+r}{r+\delta} f P_{i}^{H} .
\end{aligned}
$$

Substituting out the wage using the job-creation condition this becomes:

$$
\begin{aligned}
& \frac{(1-\delta)}{r+\delta}\left(q_{d}\left[\varphi_{i d}^{* H}\right] p_{d}\left[\varphi_{i d}^{* H}\right]-\beta_{i} p_{d}\left[\varphi_{i}^{H}\right] \varphi_{i}^{H}\left(\frac{S\left[\varphi_{i}^{H}\right]}{L\left[\varphi_{i}^{H}\right]}\right)^{\beta_{i}-1} \frac{\sigma-1}{\sigma-\beta_{i} \mu+\beta_{i} \sigma \mu-\sigma \mu} S\left[\varphi_{i d}^{* H}\right]\right) \\
& -\frac{(1-\delta)}{r+\delta}\left[\left(1-\beta_{i}\right) p_{d}\left[\varphi_{i}^{H}\right] \varphi_{i}^{H}\left(\frac{S\left[\varphi_{i}^{H}\right]}{L\left[\varphi_{i}^{H}\right]}\right)^{\beta_{i}} \frac{\sigma-1}{\sigma+\beta_{i} \mu-\mu-\beta_{i} \sigma \mu} L\left[\varphi_{i d}^{* H}\right]\right]=\frac{1+r}{r+\delta} f P_{i}^{H} .
\end{aligned}
$$


Using the linear homogeneity property of the Cobb-Dougals production function and $q\left[\varphi_{i}^{H}\right] p\left[\varphi_{i}^{H}\right]=\left(\frac{\varphi_{i}^{H}}{\varphi_{i d}^{* H}}\right)^{\sigma-1} q\left[\varphi_{i d}^{* H}\right] p\left[\varphi_{i d}^{* H}\right]$ we can write:

$$
\begin{aligned}
& \frac{(1-\delta)}{r+\delta}\left(p_{d}\left[\varphi_{i}^{H}\right] \varphi_{i}^{H} S\left[\varphi_{i}^{H}\right]_{i}^{\beta} L\left[\varphi_{i}^{H}\right]^{1-\beta_{i}}-\beta_{i} p_{d}\left[\varphi_{i}^{H}\right] \varphi_{i}^{H} S\left[\varphi_{i}^{H}\right]_{i}^{\beta} L\left[\varphi_{i}^{H}\right]^{1-\beta_{i}} \times\right. \\
& \left.\frac{\sigma-1}{\sigma-\beta_{i} \mu+\beta_{i} \sigma \mu-\sigma \mu}\right)-\frac{(1-\delta)}{r+\delta}\left(\left(1-\beta_{i}\right) p_{d}\left[\varphi_{i}^{H}\right] \varphi_{i}^{H} S\left[\varphi_{i}^{H}\right]_{i}^{\beta} L\left[\varphi_{i}^{H}\right]^{1-\beta_{i}}\right. \\
& \left.\frac{\sigma-1}{\sigma+\beta_{i} \mu-\mu-\beta_{i} \sigma \mu}\right)=\left(\frac{\varphi_{i}^{H}}{\varphi_{i d}^{* H}}\right)^{\sigma-1} \frac{1+r}{r+\delta} f P_{i}^{H} \rightarrow \\
& \frac{(1-\delta)}{r+\delta}\left(p_{d}\left[\varphi_{i}^{H}\right] \varphi_{i}^{H} S\left[\varphi_{i}^{H}\right]_{i}^{\beta} L\left[\varphi_{i}^{H}\right]^{1-\beta_{i}}\right)\left(1-\beta_{i} \frac{\sigma-1}{\sigma-\beta_{i} \mu+\beta_{i} \sigma \mu-\sigma \mu}\right. \\
& \left.-\left(1-\beta_{i}\right) \frac{\sigma-1}{\sigma+\beta_{i} \mu-\mu-\beta_{i} \sigma \mu}\right)=\left(\frac{\varphi_{i}^{H}}{\varphi_{i d}^{* H}}\right)^{\sigma-1} \frac{1+r}{r+\delta} f P_{i}^{H} .
\end{aligned}
$$

Thus, in order to ensure that quantities and prices are non-negative, the following condition has to hold:

$$
1-\beta_{i} \frac{\sigma-1}{\sigma-\beta_{i} \mu+\beta_{i} \sigma \mu-\sigma \mu}-\left(1-\beta_{i}\right) \frac{\sigma-1}{\sigma+\beta_{i} \mu-\mu-\beta_{i} \sigma \mu} \geq 0
$$

This condition gives a restriction on the possible values that can be simultaneously chosen for $\beta_{i}, \sigma$ and $\mu$. In our calibration we take care that this restriction is satisfied. 


\section{References}

Anderson, J. (2009): "Gravity, Productivity and the Pattern of Production and Trade," NBER Working Paper No. 14642.

Attanasio, O., G. Pinelopi, and N. Pavcnik (2004): "Trade Reforms and Wage Inequality in Columbia," Journal of Development Economics, 74(2), 331366.

Baldwin, R., And C. Magee (2000): Congressional Trade Votes: From NAFTA Approval to Fast-Track Defeat. Institute for International Economics, Washington, DC.

Bartelsman, E., And M. Doms (2000): "Understanding Productivity: Lessons from Longitudinal Microdata," Journal of Economic Literature, 38(3), 569-594.

Bartelsmann, E., J. Haltiwanger, and S. Scarpetta (2004): "Microeconomic Evidence of Creative Destruction in Industrial and Developing Countries," IZA Discussion Paper No. 1374.

Bernard, A., J. Eaton, J. Jensen, and S. Kortum (2003): "Plants and Productivity in International Trade," American Economic Review, 93(4), $1268-1290$.

Bernard, A., and J. Jensen (1995): "Exports, Jobs, and Wages in US Manufacturing: 1976-87," Brookings Papers on Economic Activity: Microeconomics, pp. $67-112$.

(1999): "Exceptional Exporter Performance: Cause, Effect, or Both?," Journal of International Economics, 47(1), 1-25.

(2004): "Why Some Firms Export," Review of Economics and Statistics, $86(2), 561-569$.

Bernard, A., J. Jensen, And P. Schott (2006): "Survival of the Best Fit: Exposure to Low Wage Countries and the (Uneven) Growth of U.S. Manufacturing Plants," Journal of International Economics, 68(1), 219-237.

Bernard, A., S. Redding, and P. Schott (2007): "Comparative Advantage and Heterogeneous Firms," Review of Economic Studies, 74(1), 31-66.

Blanchard, O., and F. Giavazzi (2003): "Macroeconomic Effects of Regulation and Deregulation in Goods and Labor Markets," Quarterly Journal of Economics, 118(3), 879-907. 
Clerides, S., S. Lach, and J. Tybout (1998): "Is Learning by Exporting Important? Micro-Dynamic Evidence from Columbia, Mexico, and Morocco," Quarterly Journal of Economics, 113(3), 903-947.

Davidson, C., L. Martin, and S. Matusz (1999): "Trade and Search Generated Unemployment," Journal of International Economics, 48(2), 271-299.

Davidson, C., And S. Matusz (2004): International Trade and Labor Markets - Theory, Evidence, and Policy Implications. Kalamazoo, Michigan.

Davis, S., And J. Haltiwanger (1992): "Gross Job Creation, Gross Job Destruction, and Employment Reallocation," Quarterly Journal of Economics, 107(3), 819-863.

Dunne, T., M. Roberts, and L. Samuelson (1989): "The Growth and Failure of U.S. Manufacturing Plants," Quarterly Journal of Economics, 104(4), 671-698.

Egger, H., And U. Kreickemeier (2008a): "Firm Heterogeneity and the Labour Market Effects of Trade Liberalisation," International Economic Review, forthcoming.

(2008b): "Fairness, Trade, and Inequality," GEP Research Paper 2008/19, Leverhulme Centre for Research on Globalisation and Economic Policy.

Elliott, R., And J. Lindley (2006a): "Skill Specificity and Labour Mobility: Occupational and Sectoral Dimensions," The Manchester School, 74, 389-413. (2006b): "Trade, Skills and Adjustment Costs: A Study of Intra-Sectoral Labor Mobility," Review of Development Economics, 10, 20-41.

Feenstra, R. (2004): Advanced International Trade: Theory and Evidence. Princeton University Press, Princeton, New Jersey.

Felbermayr, G., and J. Prat (2007): "Product Market Regulation, Firm Selection and Unemployment," IZA DP No. 2754.

Felbermayr, G., J. Prat, and H.-J. Schmerer (2008): "Globalization and Labor Market Outcomes: Wage Bargaining, Search Frictions, and Firm Heterogeneity," IZA DP No. 3363.

Ghironi, F., And M. Melitz (2005): "International Trade and Macroeconomic Dynamics with Heterogeneous Firms," Quarterly Journal of Economics, 120(3), 865-915. 
Greenaway, D., R. Upward, and P. Wright (2000): "Sectoral Transformation and Labour Market Flows," Oxford Review of Economic Policy, 16, $57-75$.

(2002): "Structural Adjustment and the Sectoral and Geographical Mobility of Labour," GEP working paper, 2002/18.

Hall, R. (2005): "Employment Fluctuations with Equilibrium Wage Stickiness," American Economic Review, 95(1), 50-65.

Helpman, E., and O. Itskhoki (2008): "Labor Market Rigidities, Trade and Unemployment," unpublished manuscript.

Helpman, E., O. Itskhoki, and S. Redding (2008a): "Inequality and Unemployment in a Global Economy," unpublished manuscript.

(2008b): "Wages, Unemployment and Inequality with Heterogeneous Firms and Workers," unpublished manuscript.

Hosios, A. (1990): "On the Efficiency of Matching and Related Models of Search and Unemployment," Review of Economic Studies, 57(2), 279-298.

Krugman, P. (1993): "What do Undergrads Need To Know About Trade?," American Economic Review Papers and Proceedings, 83(2), 23-26.

Levinsohn, J. (1999): "Employment Responses to International Liberalization in Chile," Journal of International Economics, 47(2), 321-344.

Melitz, M. (2003): "The Impact of Trade on Intra-Industry Reallocations and Aggregate Industry Productivity," Econometrica, 71(6), 1695-1725.

Mortensen, D., and C. Pissarides (1994): "Job Creation and Job Destruction in the Theory of Unemployment," Review of Economic Studies, 61(3), $397-415$.

OECD (2007): "Education at a Glance," http://www.oecd.org.

Petrongolo, B., And C. Pissarides (2001): "Looking into the Black Box: A Survey of the Matching Function," Journal of Economic Literature, 39(2), 390-431.

Pissarides, C. (2000): Equilibrium Unemployment Theory. The MIT Press, Cambridge, Massachusetts, 2 edn.

Roberts, M., And J. Tybout (1997): "The Decision to Export in Colombia: An Empirical Model of Entry with Sunk Costs," American Economic Review, $87(4), 545-564$. 
Shimer, R. (2005): "The Cyclical Behavior of Equilibrium Unemployment and Vacancies," American Economic Review, 95(1), 25-49.

Stole, L., and J. Zwiebel (1996): "Intra-Firm Bargaining under Non-Binding Non-Binding Contracts," Review of Economic Studies, 63(3), 375-410.

Stolper, W., And P. Samuelson (1941): "Protection and Real Wages," Review of Economic Studies, 9, 58-73.

Trefler, D. (1995): "The Case of the Missing Trade and Other Mysteries," American Economic Review, 85(5), 1029-1046. 


\section{CESifo Working Paper Series}

for full list see www.cesifo-group.org/wp

(address: Poschingerstr. 5, 81679 Munich, Germany, office@cesifo.de)

2689 Alexander Chudik, M. Hashem Pesaran and Elisa Tosetti, Weak and Strong Cross Section Dependence and Estimation of Large Panels, June 2009

2690 Mohamed El Hedi Arouri and Christophe Rault, On the Influence of Oil Prices on Stock Markets: Evidence from Panel Analysis in GCC Countries, June 2009

2691 Lars P. Feld and Christoph A. Schaltegger, Political Stability and Fiscal Policy - Time Series Evidence for the Swiss Federal Level since 1849, June 2009

2692 Michael Funke and Marc Gronwald, A Convex Hull Approach to Counterfactual Analysis of Trade Openness and Growth, June 2009

2693 Patricia Funk and Christina Gathmann, Does Direct Democracy Reduce the Size of Government? New Evidence from Historical Data, 1890-2000, June 2009

2694 Kirsten Wandschneider and Nikolaus Wolf, Shooting on a Moving Target: Explaining European Bank Rates during the Interwar Period, June 2009

2695 J. Atsu Amegashie, Third-Party Intervention in Conflicts and the Indirect Samaritan's Dilemma, June 2009

2696 Enrico Spolaore and Romain Wacziarg, War and Relatedness, June 2009

2697 Steven Brakman, Charles van Marrewijk and Arjen van Witteloostuijn, Market Liberalization in the European Natural Gas Market - the Importance of Capacity Constraints and Efficiency Differences, July 2009

2698 Huifang Tian, John Whalley and Yuezhou Cai, Trade Sanctions, Financial Transfers and BRIC's Participation in Global Climate Change Negotiations, July 2009

2699 Axel Dreher and Justina A. V. Fischer, Government Decentralization as a Disincentive for Transnational Terror? An Empirical Analysis, July 2009

2700 Balázs Égert, Tomasz Koźluk and Douglas Sutherland, Infrastructure and Growth: Empirical Evidence, July 2009

2701 Felix Bierbrauer, Optimal Income Taxation and Public Goods Provision in a Large Economy with Aggregate Uncertainty, July 2009

2702 Marc Gronwald, Investigating the U.S. Oil-Macroeconomy Nexus using Rolling Impulse Responses, July 2009

2703 Ali Bayar and Bram Smeets, Government Deficits in the European Union: An Analysis of Entry and Exit Dynamics, July 2009 
2704 Stergios Skaperdas, The Costs of Organized Violence: A Review of the Evidence, July 2009

2705 António Afonso and Christophe Rault, Spend-and-tax: A Panel Data Investigation for the EU, July 2009

2706 Bruno S. Frey, Punishment - and beyond, July 2009

2707 Michael Melvin and Mark P. Taylor, The Crisis in the Foreign Exchange Market, July 2009

2708 Firouz Gahvari, Friedman Rule in a Model with Endogenous Growth and Cash-inadvance Constraint, July 2009

2709 Jon H. Fiva and Gisle James Natvik, Do Re-election Probabilities Influence Public Investment?, July 2009

2710 Jarko Fidrmuc and Iikka Korhonen, The Impact of the Global Financial Crisis on Business Cycles in Asian Emerging Economies, July 2009

2711 J. Atsu Amegashie, Incomplete Property Rights and Overinvestment, July 2009

2712 Frank R. Lichtenberg, Response to Baker and Fugh-Berman's Critique of my Paper, "Why has Longevity Increased more in some States than in others?", July 2009

2713 Hans Jarle Kind, Tore Nilssen and Lars Sørgard, Business Models for Media Firms: Does Competition Matter for how they Raise Revenue?, July 2009

2714 Beatrix Brügger, Rafael Lalive and Josef Zweimüller, Does Culture Affect Unemployment? Evidence from the Röstigraben, July 2009

2715 Oliver Falck, Michael Fritsch and Stephan Heblich, Bohemians, Human Capital, and Regional Economic Growth, July 2009

2716 Wladimir Raymond, Pierre Mohnen, Franz Palm and Sybrand Schim van der Loeff, Innovative Sales, R\&D and Total Innovation Expenditures: Panel Evidence on their Dynamics, July 2009

2717 Ben J. Heijdra and Jochen O. Mierau, Annuity Market Imperfection, Retirement and Economic Growth, July 2009

2718 Kai Carstensen, Oliver Hülsewig and Timo Wollmershäuser, Price Dispersion in the Euro Area: The Case of a Symmetric Oil Price Shock, July 2009

2719 Katri Kosonen and Gaëtan Nicodème, The Role of Fiscal Instruments in Environmental Policy, July 2009

2720 Guglielmo Maria Caporale, Luca Onorante and Paolo Paesani, Inflation and Inflation Uncertainty in the Euro Area, July 2009 
2721 Thushyanthan Baskaran and Lars P. Feld, Fiscal Decentralization and Economic Growth in OECD Countries: Is there a Relationship?, July 2009

2722 Nadia Fiorino and Roberto Ricciuti, Interest Groups and Government Spending in Italy, 1876-1913, July 2009

2723 Andreas Wagener, Tax Competition, Relative Performance and Policy Imitation, July 2009

2724 Hans Fehr and Fabian Kindermann, Pension Funding and Individual Accounts in Economies with Life-cyclers and Myopes, July 2009

2725 Ernesto Reuben and Arno Riedl, Enforcement of Contribution Norms in Public Good Games with Heterogeneous Populations, July 2009

2726 Kurt Schmidheiny and Marius Brülhart, On the Equivalence of Location Choice Models: Conditional Logit, Nested Logit and Poisson, July 2009

2727 Bruno S. Frey, A Multiplicity of Approaches to Institutional Analysis. Applications to the Government and the Arts, July 2009

2728 Giovanni Villani, A Strategic R\&D Investment with Flexible Development Time in Real Option Game Analysis, July 2009

2729 Luca Di Corato and Michele Moretto, Investing in Biogas: Timing, Technological Choice and the Value of Flexibility from Inputs Mix, July 2009

2730 Gilad D. Aharonovitz, Nathan Skuza and Faysal Fahs, Can Integrity Replace Institutions? Theory and Evidence, July 2009

2731 Michele Moretto and Sergio Vergalli, Managing Migration through Conflicting Policies: an Option-theory Perspective, July 2009

2732 Volker Nitsch, Fly or Cry: Is Airport Noise Costly?, July 2009

2733 Francesco Cinnirella and Joachim Winter, Size Matters! Body Height and Labor Market Discrimination: A Cross-European Analysis, July 2009

2734 Samuel Bowles and Sandra Polanía Reyes, Economic Incentives and Social Preferences: A Preference-based Lucas Critique of Public Policy, July 2009

2735 Gary Burtless, Lessons of the Financial Crisis for the Design of National Pension Systems, July 2009

2736 Helmuth Cremer, Firouz Gahvari and Pierre Pestieau, Fertility, Human Capital Accumulation, and the Pension System, July 2009

2737 Hans Jarle Kind and Frank Stähler, Market Shares in Two-Sided Media Industries, July 2009 
2738 Pamela Campa, Alessandra Casarico and Paola Profeta, Gender Culture and Gender Gap in Employment, August 2009

2739 Sebastian Gechert, Supplementary Private Health Insurance in Selected Countries: Lessons for EU Governments?, August 2009

2740 Leif Danziger, Endogenous Monopsony and the Perverse Effect of the Minimum Wage in Small Firms, August 2009

2741 Yan Dong and John Whalley, A Third Benefit of Joint Non-OPEC Carbon Taxes: Transferring OPEC Monopoly Rent, August 2009

2742 Valentina Bosetti, Carlo Carraro and Massimo Tavoni, Climate Change Mitigation Strategies in Fast-Growing Countries: The Benefits of Early Action, August 2009

2743 Christina Felfe, The Willingness to Pay for Job Amenities: Evidence from Mothers' Return to Work, August 2009

2744 Jörg Franke, Christian Kanzow, Wolfgang Leininger and Alexandra Väth, Effort Maximization in Asymmetric N-Person Contest Games, August 2009

2745 Bruno S. Frey and Paolo Pamini, Making World Heritage Truly Global: The Culture Certificate Scheme, August 2009

2746 Frank N. Caliendo, Is Social Security behind the Collapse of Personal Saving?, August 2009

2747 Caterina Liesegang and Marco Runkel, Corporate Income Taxation of Multinationals and Fiscal Equalization, August 2009

2748 Chrysovalantou Milliou and Apostolis Pavlou, Upstream Horizontal Mergers and Efficiency Gains, August 2009

2749 Rüdiger Pethig and Christian Wittlich, Interaction of Carbon Reduction and Green Energy Promotion in a Small Fossil-Fuel Importing Economy, August 2009

2750 Kai Carstensen, Oliver Hülsewig and Timo Wollmershäuser, Monetary Policy Transmission and House Prices: European Cross-country Evidence, August 2009

2751 Olaf Posch, Explaining Output Volatility: The Case of Taxation, August 2009

2752 Beatrice Scheubel, Daniel Schunk and Joachim Winter, Don't Raise the Retirement Age! An Experiment on Opposition to Pension Reforms and East-West Differences in Germany, August 2009

2753 Daniel G. Arce, Dan Kovenock and Brian Roberson, Suicide Terrorism and the Weakest Link, August 2009

2754 Mario Larch and Wolfgang Lechthaler, Comparative Advantage and Skill-Specific Unemployment, August 2009 